\title{
Present status and perspectives of endosonography 2017 in gastroenterology
}

\author{
Michael Hocke ${ }^{1}$, Barbara Braden ${ }^{2}$, Christian Jenssen ${ }^{3}$, and Christoph F. Dietrich ${ }^{4}$
}

\author{
${ }^{1}$ Internal Medicine II, Helios Hospital \\ Meiningen, Germany; ${ }^{2}$ Translational \\ Gastroenterology Unit, Oxford \\ University Hospitals, Oxford, UK; \\ ${ }^{3}$ Medical Department, Maerkisch- \\ Oderland Hospital, Strausberg; \\ ${ }^{4}$ Medical Department 2, Caritas \\ Hospital Bad Mergentheim, Bad \\ Mergentheim, Germany
}

Received: June 5, 2017

Accepted: June 16, 2017

\section{Correspondence to}

Christoph F. Dietrich, M.D.

Medical Department 2, Caritas

Hospital Bad Mergentheim,

Uhlandstraße 7, Bad

Mergentheim 97980, Germany

Tel: +49-7931-582201

Fax: $+49-7931-582290$

E-mail: Christoph.dietrich@ckbm.de
Endoscopic ultrasound has become an essential tool in modern gastroenterology and abdominal surgery. Compared with all other endoscopic methods, it has the most potential for innovation and its future looks bright. Thus, we compiled this summary of established and novel applications of endoscopic ultrasound methods to inform the reader about what is already possible and where future developments will lead in improving patient care further. This review is structured in four parts. The first section reports on developments in diagnostic endoscopic ultrasound, the second looks at semi-invasive endoscopic ultrasound, and the third discusses advances in therapeutic endoscopic ultrasound. An overview on the future prospects of endoscopic ultrasound methods concludes this article.

Keywords: Endosonography; Endoscopic ultrasound-guided fine needle aspiration; Contrast enhanced endoscopic ultrasound; Endoscopic ultrasound elastography; Endoscopic ultrasound-guided drainage

\section{INTRODUCTION}

First experimental experience with endoscopic ultrasound was published in the years between 1978 and 1980 by several groups in Germany, the United States of America, and Japan. Already in 1982 the first commercially available radial echoendocope was presented by Olympus (Tokyo, Japan). Since these early years, endoscopic ultrasound has become an indispensable part of the toolbox of gastroenterology, pulmonology, and oncological visceral medicine. Combining superior visualization of difficult to explore anatomical regions of the human body and guidance of transmural access it has expanded largely the armamentarium of diagnostic and therapeutical techniques in gastroenterology. This review summarizes the most important indications and achievements of diagnostic and therapeutic endoscopic ultrasound in gastroenterology and highlights its most recent developments and perspectives.

\section{DIAGNOSTIC ENDOSCOPIC ULTRASOUND}

Multiple technical developments have changed the diagnostic endoscopic ultrasound (EUS) of the past. The method was mainly used for staging purposes of gastrointestinal tumors in the early days; however, its main diagnostic role now concerns the assessment of organs surrounding the gastrointestinal tract. In particular, the diagnosis of pancreaticobiliary diseases is currently the 
most often performed application of EUS.

\section{Staging of gastrointestinal tumors}

B-mode EUS remains the method with the highest resolution for local staging of esophageal, gastric, and rectal tumors [1-3] and is recommended in most current guidelines for cancer management. The advantage of EUS lies in the detailed visualization of the wall layers of the gastrointestinal tract, which is not possible with any other method, except percutaneous ultrasound in selected patients. Such high-resolution imaging of the gastrointestinal wall enables preoperative T-staging. Unfortunately, EUS as a staging tool still has several limitations. Peritumoral inflammation or microinvasive features of tumors can result in significant over- and under-staging $[4,5]$. This is true even for high-resolution EUS with 20 $\mathrm{MHz}$ probes [6]. Thus, only an approximate staging is possible, especially in view of the updated pathologystaging classification of stomach cancer, which puts a cancer with perforation through the serosa already into stage 4a. The serosa is a thin layer of only a few cells in thickness and cannot be adequately displayed using EUS [7].

Despite the known limitations of the method, EUS currently remains the most important and most accurate local staging method for gastrointestinal cancers. This is especially true for the staging of early gastric and esophageal cancer, where involvement of the mucosal or submucosal layers predicts lymph node involvement. In clinical practice, it is sufficient to diagnose invasion of the muscularis propria and of local lymph nodes correctly to obviate an endoscopic resection (Fig. 1) [6]. Discrimination of $\mathrm{T}_{2}$ and $\mathrm{T}_{3}$ tumors can be made with sufficient accuracy. This discrimination is important because it is an oncological "watershed" between direct surgery or neoadjuvant treatment concepts, knowing that T2 also implies neoadjuvant treatment under certain circumstances [8].

Lymph node staging using EUS has weaknesses too [9]. Again, the biology of the tumor has to be taken into account. Even if all lymph nodes in the area adjacent to the tumor should be considered malignant, reliable discrimination between malignant and benign lymph nodes is not possible using B-mode EUS alone. It has to be considered that even a few tumor cells seen microscopically within an otherwise morphologically nor- mal lymph node would be staged as a malignant lymph node. This exceeds the maximum resolution of any diagnostic imaging technique and, thus, is not finally answerable. Particularly in gastric cancer, $\mathrm{N}$-staging is defined by the number of lymph nodes involved. Because of the uncertainty in counting suspected lymph nodes using EUS alone, the terms $\mathrm{N}+$ and $\mathrm{N}-$ should be reported, whereas attempts to quantify as $\mathrm{N}_{1}, \mathrm{~N}_{2}$, or $\mathrm{N}_{3}$ should be avoided [10].

To improve the staging of gastrointestinal tumors, modern methods, such as elastography and contrast-enhanced EUS, have been examined [11-13]. Unfortunately these methods do not improve the quality of the staging and, thus, have not influenced clinical practice [1]. This is true for $\mathrm{T}$ as well as $\mathrm{N}$ staging [14-16].

While the staging of gastrointestinal tumors should be performed only in histologically proven cancers, this is more challenging in scirrhous gastric cancer or linitis plastic because of the special tumor behavior. Superficial mucosal biopsies can be falsely negative because the tumor can hide in the deeper gastric areas and is hard to discriminate from Menetrier's disease with thickened gastric folds. In this condition, EUS can be used in the differential diagnosis because of the pathognomonic thickening of all gastric layers, with loss of separation. The behavior is so typical that a gastrectomy can be justified even without preoperative histological confirmation [17].

One special type of gastrointestinal tumor is the periampullary tumor. Again, EUS is the method of choice

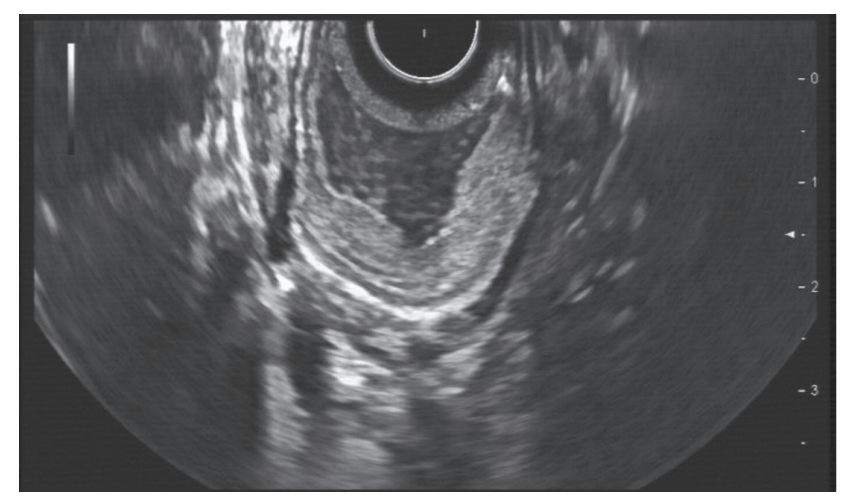

Figure 1. Endoscopic ultrasound imaging of an early gastric cancer. Modern endoscopic equipment can display the layers with very high resolution, even at $7.5 \mathrm{MHz}$. In the right part of the image, tumor invasion of the deep submucosal layer, but not the muscularis propria, is visible (stage $\mathrm{uTib}$ ). 
for locoregional staging purposes [10]. Knowing the differential diagnosis of periampullary tumors is key to avoiding therapeutic mistakes. A common but clinically insignificant entity is adenomyomatosis of the papilla of Vater. The adenomyomatosis is a benign hypertrophy of the muscle of the papilla, which is especially common in older women and patients after cholecystectomy. The normally very circumscribed ampullary lesion without signs of invasion can appear quite irregular at the end of the common bile duct, which may lead to misinterpretation [18].

One differential diagnosis of such an adenomyomatosis is a true adenoma of the papilla; however, this is usually not a diagnostic problem because of the mostly luminal growth of the tumor and, thus, the easy opportunity to it visualize endoscopically and take a biopsy for histological confirmation. EUS should be able to predict resectability and to visualize local pathological lymph nodes, indicating malignant transformation [19].

EUS is also the imaging method of choice for the assessment of periampullary carcinomas. Especially in the advanced stages, the differentiation of a papillary carcinoma with infiltration of the pancreas from a pancreatic carcinoma with infiltration of the papilla region may be difficult [20].

\section{What is really new?}

Nothing at all. Endosonography remains the mainstay in locoregional staging of upper gastrointestinal tumors, is a supplementary tool in rectal cancer staging, and has no significant role in re-staging after neoadjuvant treatment. EUS-guided fine-needle aspiration (FNA) of nonregional lymph nodes and suspected distant metastases change the course of management in $\sim 10 \%$ of patients. No new technical development has significantly improved the staging accuracy of endosonography.

\section{Diagnosis of subepithelial tumors}

Subepithelial tumors of the gastrointestinal tract often require EUS for further characterization, diagnosis, and tissue acquisition. Again, the localization of the tumor in relation to the wall layers is of the utmost importance in further management $[21,22]$. However, the accuracy of the final diagnosis made by EUS has to be considered critically. Whereas intraobserver agreement in cases of cystic lesions is very high, there is only a moderate agreement with lipomas and typically poor agreement regarding other, rather uncommon, solid lesions [23]. Cystic lesions can be classified by EUS into common gastrointestinal cysts and duplication cysts. A common cyst is localized in the submucosa and splits up the wall layers, whereas a duplication cyst shows all wall layers on both sides [24]. Lipomas are also localized in the submucosa and are typically homogeneously echorich [25]. Because of their fatty content and poor vascularization, these lesions are soft in elastography and do not take up contrast agents in contrast-enhanced EUS [26]. Other solid subepithelial tumors are also hard to diagnose and characterize. Twenty years ago, basically every echopoor well circumscribed tumor was classified as a leiomyoma. Since the discovery of gastrointestinal stromal tumors (GISTs), the differential diagnosis, especially for small solid tumors, has become more challenging. Because most of these tumors are GISTs when localized in the stomach and are leiomyomas when localized in the esophagus, a preliminary diagnosis can be made simply, according to localization [26]. However, even a GIST may not be a GIST because there are GIST tumors with low mitotic rates and more aggressive entities with higher mitotic rates. Because of missing pathognomonic signs in endosonography and other imaging modalities, the therapeutic management is based on the localization and size of the tumors. Tumors that are localized in the mucosal layer can be removed endoscopically by snare resection. This is not possible with most tumors localized in the outer muscle layer of the stomach. Small tumors can be removed by endoscopic dissection or using the full-thickness resection device (FTRD)-system from Ovesco (Tubingen, Germany), but most cases will need transabdominal surgery. Surgery is indicated for GISTs larger than $3 \mathrm{~cm}$ because of the higher malignant potential according to the size of the tumor [27]. In patients with a tumor size between 1 and $3 \mathrm{~cm}$, endoscopic fine-needle puncture can be performed to detect potentially malignant GISTs, which would prompt early surgical removal. However, material that is sufficient for a definite differentiation between harmless leiomyoma or Schwannoma on the one hand and potentially malignant GIST on the other is possible in only $\sim 60 \%$ of cases [28]. Modern diagnostic EUS methods, such as elastography and contrast-enhanced endosonography, aim to assess the malignant potential of tumors by special im- 

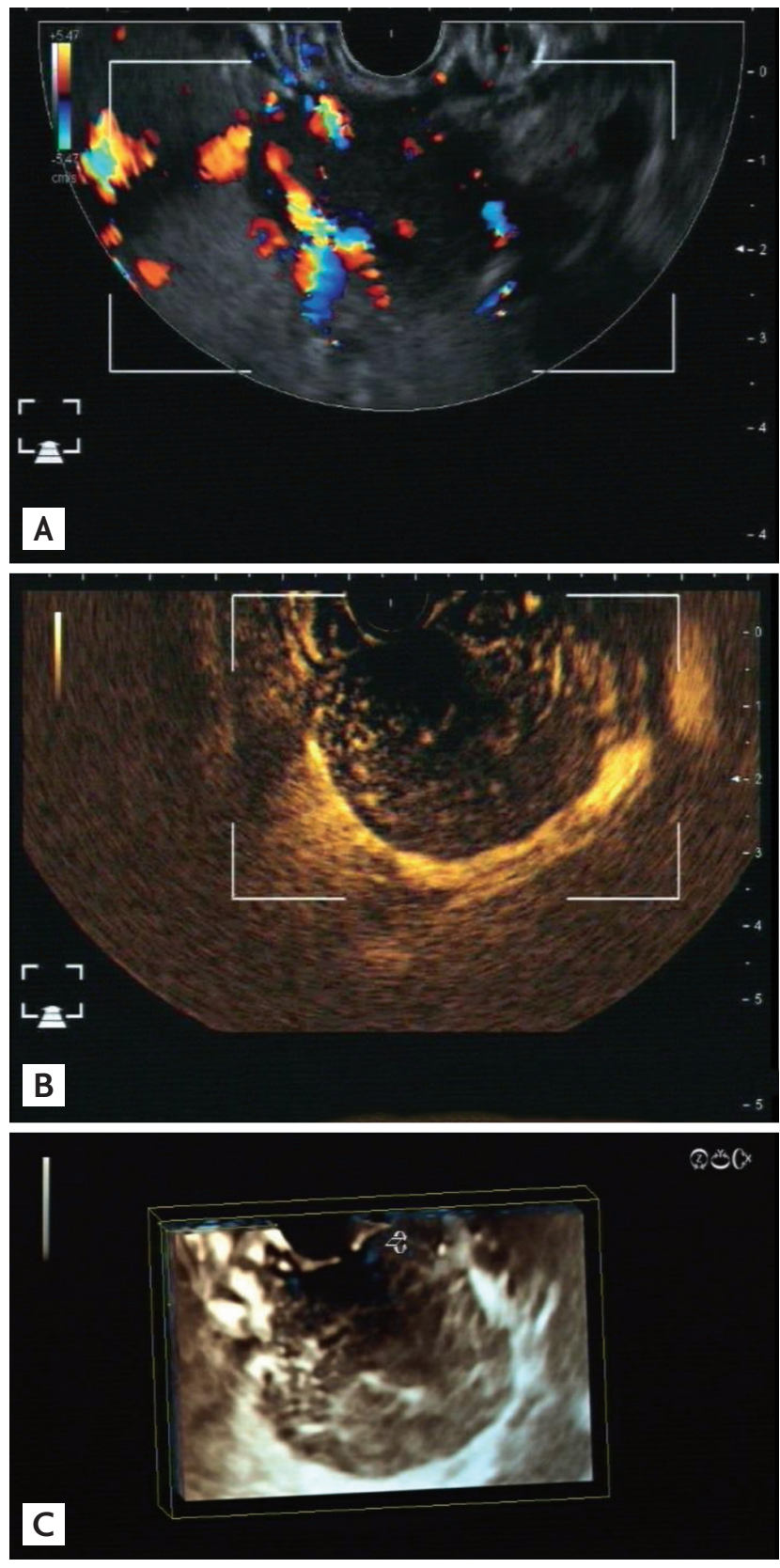

Figure 2. Endoscopic ultrasound of a gastrointestinal stromal tumor in the upper stomach originating from the muscularis propria. (A) The tumor is well circumscribed and has a homogeneous echo pattern. Note the vessels in color Doppler mode. (B) Following injection of $4.8 \mathrm{~mL}$ Sonovue (Bracco), strong contrast enhancement occurred within the tumor, with the exception of a necrotic area near the ultrasound probe. (C) Using three-dimensional reconstruction the non-enhancing necrotic area and vessel architecture are clearly visible.

aging features, and several studies have been performed in GISTs [29-31]. The less hard a tumor is, using elastography, the higher is its malignant potential. Using contrast-enhanced EUS, there was a difference between leiomyomas and other benign subepithelial gastrointestinal tumors, which typically show poor vascularization, and GISTs, with a typically rich vascularization and necrotic areas, especially when bigger than $2 \mathrm{~cm}$ (Fig. 2) [26,31-33]. Moreover, the malignancy risk of GISTs may be predicted by visualizing neovascularization and avascular necrotic areas $[29,34,35]$. These criteria are indicative of the nature of the lesion but cannot replace a cytological or histological examination.

Another common subepithelial lesion is the ectopic pancreas or pancreatic rest (Fig. 3). Because of the inhomogeneous structure of the lesion, it is easy to misdiagnose it as a malignant lesion $[36,37]$. A pancreatic rest can appear invasive and is usually not well circumscribed. The lesion does not exceed the outer border of the stomach and should not show regional lymph node enlargement. Typically, the diagnosis can be made based on the typical endoscopic appearance with the central naval [38].

There are other, rare subepithelial lesions, such as Schwannomas, leiomyosarcomas, or metastases of a malignant melanoma, and other tumors that lack distinctive ultrasound features. Thus, a diagnosis can only be made by cytology/histology [39].

\section{What is really new?}

Contrast-enhanced endosonography is a valuable additional tool for the differentiation of GIST from benign mesenchymal subepithelial tumors and for risk stratification. EUS-FNA with immunocytochemistry can establish a definite diagnosis in $60 \%$ of cases.

\section{Diagnosis of cholangiolithiasis}

EUS is the most sensitive diagnostic method to detect bile duct stones $[40,41]$. Regarding the detection of gallstones in the common bile duct, EUS exceeds all other methods including endoscopic retrograde cholangiography (ERC) if the bile duct is visible. Conditions with an impaired view or accessibility of the bile duct, like a Billroth II operation or aerobilia, are exceptions [42]. Because of the significantly lower complication rate, EUS replaced ERC in the diagnosis of cholangiolithiasis [43]. Gallstone removal is indicated as an emergency procedure in cholangitis or biliary pancreatitis. In some cases, preliminary imaging tests (percutaneous ultra- 
sound, computed tomography [CT], or even magnetic resonance cholangiopancreatography) may not be conclusive. In these situations, EUS might emerge, even as an emergency procedure, to guide therapeutic decisions [44]. Modern longitudinal scanners can also be used as duodenoscopes for immediate stone removal [45]. However, in clinical practice, this point can be neglected due to the only slight delay caused by exchanging instruments. Because of the pathognomonic endosonographic display of bile duct stones, additional diagnostic procedures are rarely necessary (Fig. 4) [46].

What is really new?

Nothing.

\section{Pancreas}

Diagnosis of "minimal change" chronic pancreatitis

The high resolution of EUS makes it possible to display changes in the pancreatic tissue that cannot be seen in any other way [47]. However, without guidance in context, such changes can be overrated. Thus, the implementation of a scoring system, like the Rosemont criteria, was inevitable [48]. The initial assumption that a minimal change in disease might evolve to severe, chronic pancreatitis over time did not prove correct. In most cases, the disease does not progress, although the evidence for this is still limited [49]. Most patients with minimal signs of chronic pancreatitis have non-specific abdominal discomfort and temporarily elevated pancre-

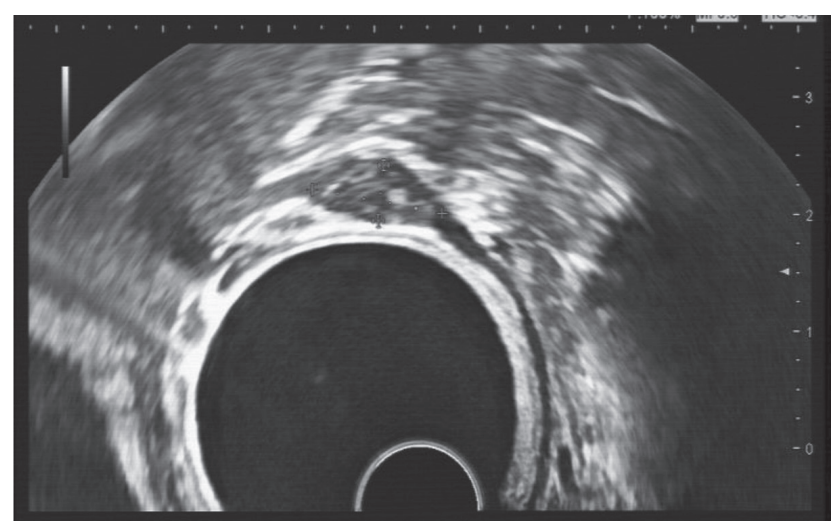

Figure 3. Ectopic pancreas in the antral region of the stomach; the lesion can be seen in the middle upper area of the stomach next to the balloon. Note the inhomogeneous echo-pattern and the pseudoinfiltration of the muscularis propria, which does not exceed its outer margin. The lesion resembles a small part of pancreatic tissue. atic enzymes, without a clinical picture of acute pancreatitis. The Rosemont criteria provide the endoscopist with a solid diagnostic basis, although the classification appears complex because it requires calculation of main and side criteria. Interestingly, a Canadian study showed that the initial impression of an experienced endoscopist could have the same diagnostic value as the calculation of the Rosemont criteria and concluded that the calculation does not have to be performed in clinical practice [50]. Similar changes in the pancreatic parenchyma can be seen in the early stages of autoimmune pancreatitis, as described in the next section.

An interesting but not well-known phenomenon for assessing peripancreatic inflammation is the impaired mobility of the organ with position changes, which can also be assessed by ultrasound [51].

\section{Autoimmune pancreatitis}

Autoimmune pancreatitis constitutes the majority of cases in immunoglobulin $\mathrm{G}_{4}$ (IgG4)-related diseases [52]. The disease is rarely confined to the pancreas and is most often associated with other immune-related changes, such as involvement of the extrahepatic bile duct or retroperitoneum [53]. Recurrent pancreatitis with no clear history of alcohol involvement is indicative. There are two different types of the disease: the IgG4-related type and the IgG4-negative granulocyte-related type. The initial appearance in EUS shows a circumscribed or diffuse hypoechoic transformation and, typically, the pancreatic

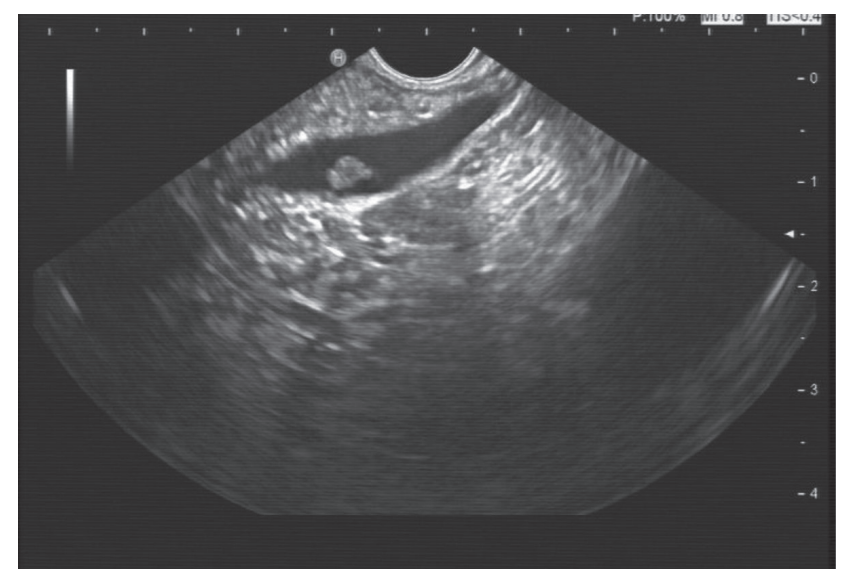

Figure 4. B-mode endoscopic ultrasound display of a small bile stone near the papilla of Vater (linear probe). The echogenic stone has a diameter of only $5 \mathrm{~mm}$ and a small acoustic shadow. The Vaters papilla is on the right side of the stone. Note that the bile duct is not enlarged ( $5 \mathrm{~mm}$ in size). 
duct is of very small caliber. Using contrast-enhanced Doppler or harmonic endosonography, hypervascularization of the pancreas is a typical finding. If autoimmune inflammation progresses, the B-mode picture often resembles a minimal-change chronic pancreatitis [54-56]. Another common phenomenon is the increased stiffness of the whole organ in elastography [57]. In symptomatic cases with elevated levels of $\mathrm{IgG}_{4}$ in a blood test and the typical endosonographic appearance, a probatory steroid therapy is indicated $[58,59]$. In cases of diagnostic uncertainty, a cytological or histological confirmation should be a goal [6o]. However, EUS-guided sampling using a 22-gauge $(G)$ needle has only limited yield and rarely helps to substantiate a definite diagnosis $[61,62]$. Autoimmune pancreatitis should always be considered in unclear symptomatic pancreatic masses and should prompt the right diagnostic decisions to avoid unnecessary pancreatic operations.

\section{Pancreas divisum}

There is continuing debate as to whether pancreas divisum can also lead to recurrent acute pancreatitis. It might be considered in patients with recurrent acute pancreatitis without a history of increased alcohol intake. In those cases, the main pancreatic duct does not connect to the duct of the ventral part of the pancreas, which could lead to a relative stenosis. EUS is not the method of choice to diagnose the entity because it is not always possible to follow the pancreatic duct around the pancreatic head. The "crossing sign" may be indicative of pancreas divisum in which the bile duct crosses the slightly enlarged pancreatic duct, which ends at the minor papilla [63]. Seeing the crossing sign, however, does not prove the disconnection of the pancreatic ducts and cannot be used as a diagnostic proof of pancreas divisum. Another indicative sign is the caliber difference of the pancreatic duct near the major papilla in relation to the pancreatic duct in the pancreatic body and tail. In cases of pancreas divisum, the pancreatic duct in the pancreatic head is small-to-not-visible and enlarged in the body and tail. If a continuous scanning of the pancreatic duct into the tail without duct discontinuation is possible, then pancreas divisum can be ruled out [64]. A pitfall for inexperienced endoscopists is to suspect a pancreas divisum based on the sometimes echopoor ventral part of the pancreas in relation to the echorich dorsal part of the pancreas. This phenomenon is due to a difference in fat content of the pancreatic tissue and does not have a pathological impact.

\section{Diagnosis of the ductal pancreatic carcinoma}

EUS seems to be the most sensitive method for diagnosing (excluding) ductal adenocarcinoma of the pancreas [65]. The high resolution of the method can visualize pancreatic lesions as small as 5 to $15 \mathrm{~mm}$ [66]. The Bmode criteria of pancreatic cancer are hypoechogenic homogeneous lesions with poor demarcation and invasive behavior. The main criterion, however, is the downstream enlargement of the pancreatic duct. Nearly all adenocarcinomas of the pancreas originate from the ductal epithelia and lead to stenosis of the duct [67]. Especially in small tumors, differential diagnosis can be difficult and, thus, diagnostic methods in addition to the B-mode diagnostic are recommended. In a large retrospective multicenter study, only $37 \%$ of all incidentally detected solid pancreatic lesions finally proved to be ductal adenocarcinomas [66]. The simple use of color Doppler ultrasound already provides valuable information. A pancreatic carcinoma does usually not show any vessels within the lesion, whereas neuroendocrine tumors are highly vascularized [68]. Pancreatic carcinomas are usually hard, which leads to the corresponding blue coding in elastography [69]. In contrast, in harmonic EUS, the typically poor vascularization in pancreatic cancer can be displayed even better without the blooming effect of Doppler mode and this allows the differentiation from other pancreatic tumors, such as neuroendocrine tumors, metastasis of renal carcinoma and small cell lung cancer, or infiltration by a lymphoma, even in very small lesions $[56,66,70]$. In the current guidelines of the European Federation of Societies of Ultrasound in Medicine and Biology (EFSUMB), contrast harmonic (endoscopic) ultrasound is recommended to determine whether EUS-FNA cytology exam should be performed, even in small resectable pancreatic lesions [71-80].

EUS is also recommended for local staging in small pancreatic tumors; however, it has problems with larger tumors, due to the limited depth of penetration. For correct tumor staging, a combination of EUS and CT scan is preferable [81]. Even with the best possible staging method, a surgical exploration of potentially resectable tumors may be justified because surgery provides 
the only curative treatment in a disease with a very poor prognosis.

A major diagnostic dilemma is the differentiation between pancreatic carcinoma and chronic (focal) pancreatitis. Because of the similar behavior of both diseases, there is currently no reliable imaging method available that can distinguish the entities [82]. However, advanced EUS can provide helpful information to support the differentiation. Currently, there are two different contrastenhanced methods in EUS. With the methods, two different levels of vascularization can be observed [83]. The latest development, called contrast harmonic imaging (CHI), allows the investigation of the capillary network of a lesion; the older method, of contrast-enhanced color Doppler EUS, can only display the level of arterioles and venules [12]. The advantage of the older method is its capability of distinguishing arterioles and venules using pulsed wave Doppler, and this has proved useful in discriminating an inflammatory process from a cancerous lesion.

Performing CHI EUS allows the display of a single contrast bubble, which is roughly the size of an erythrocyte. This means that every minuscule part of the lesion, where an erythrocyte can pass through, can be displayed as a perfused area. Basically, this method is similar to a CT or magnetic resonance imaging (MRI) scan with contrast enhancement. The main advantage of the CHI method, however, is the real-time display of the influx of the contrast agent over a period of $\sim 5$ minutes. An important difference is that the ultrasound contrast enhancer is a pure blood pool contrast enhancer and does not create any diffusion artifacts, unlike CT or MRI contrast enhancers [11]. Another advantage is that the contrast study is independent of the body blood circulation time because of the continuous scanning. The method has the same pitfalls as MRI and CT regarding the discrimination of malignant and inflammatory lesions. The assumption that a carcinoma is poorly vascularized and, therefore, does not take up the contrast-enhancing agent can be misleading in chronic pancreatitis because of inflammatory fibrosis of the capillary bed, which has the same effect [84].

An interesting fact is that the fibrotic changes do not affect the arterioles or venules. Analyzing those vessels can improve the differential diagnosis considerably. An inflammatory lesion shows a distinctive vessel system of net-like homogeneous vessels with arterial and venous vessels side by side. This is fundamentally different from the neovascularization of an adenocarcinoma, where venous vessels cannot be visualized at all and the arterial vessels are diminished and irregular $[68,76,78,83,85]$. To differentiate those small vessels, pulsed-wave Doppler is essential and, thus, EUS provides the only technique, to date, that has sufficiently high resolution and the technical capabilities to analyze these vessels. The method achieves over $90 \%$ sensitivity and specificity in the discrimination of chronic pancreatitis from pancreatic carcinoma and, thus, was included as a recommendation level A, Ia in the current guidelines of the EFSUMB (Fig. 5) [71].

The use of strain elastography for differential diagnosis of chronic pancreatitis and pancreatic carcinoma is a matter of discussion [86]. Despite a very high sensitivity, over $90 \%$, it has low specificity and, thus, is unsuitable for clinical practice [57,79]. Perhaps the use of computeraided automatic analysis software of a long video clip could improve the specificity, due to marginal differences that are not readily visible by the human eye, but further studies are required to introduce those systems into daily routine [87-89]. From surgery, however, it is known that pancreatic tissue with chronic inflammation feels similar in consistency to pancreatic cancer, so the chances seem to be low of reaching a reliable result using elastography.

\section{Neuroendocrine tumors of the pancreas}

Neuroendocrine tumors are seldom a problem in differential diagnosis of a pancreatic lesion because they are usually located within unchanged pancreatic tissue in the pancreatic tail. The lesions can be hyper- or hypoechogenic but do normally not infiltrate the pancreatic duct and, thus, do not show duct enlargement or retention pancreatitis. Sometimes, they may contain cystic components. Most of the tumors are well circumscribed and iso- or hypervascularized [9o]. This can usually already be seen in an unenhanced Doppler EUS [91]. To date, CHI mode can improve the display of the hypervascularization of the tumor but this is not absolutely necessary $[66,90,92]$. In cases of hormone-active tumors, the clinical picture leads the way to the differential diagnosis of an unclear pancreatic lesion. 

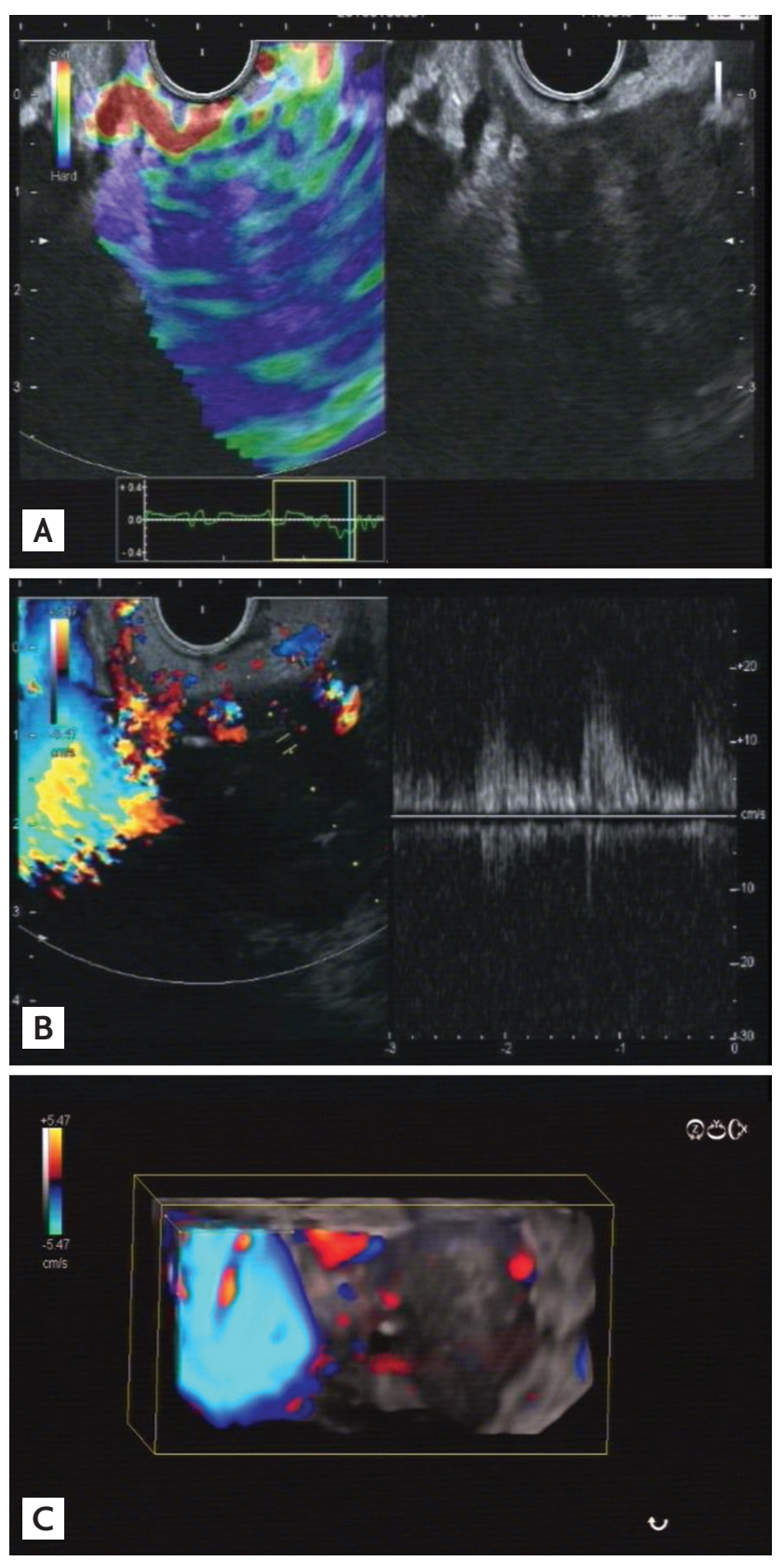

Figure 5. (A) Adenocarcinoma in the pancreatic head; note, the blue coding of the elastography as a sign of a hard tissue. (B) Adenocarcinoma of the pancreas in contrast-enhanced color Doppler mode after injection of $4.5 \mathrm{~mL}$ Sonovue (Bracco). Only a few vessels are detectable, all of them showing an arterial flow pattern in pulsed-wave Doppler. (C) Three-dimensional reconstruction of the tumor in B-mode combined with contrast-enhanced color Doppler mode: the tumor is relatively well circumscribed and is not infiltrated with arterial vessels.

\section{Metastasis of the pancreas}

In principle, every tumor can produce pancreatic me- tastasis, due to the hematological distribution of tumor cells. In B-mode ultrasound, basically, all different ultrasound characteristics can be displayed [93]. The differential diagnosis is mostly clinical, based on the presence of a known primary tumor or a past history of a tumor. Duct involvement by a metastasis is rare because of the localization of the tumor in the pancreatic parenchyma. A typical tumor metastasis in the pancreas can be seen in patients with kidney tumors, even if the actual disease was 10 to 20 years earlier [94]. Also not uncommon is a metastasis of a small-cell lung carcinoma or infiltration by a non-Hodgkin lymphoma $[95,96]$. All three entities are characterized by hypervascularization of the lesion, which can be used as a criterion to discriminate those lesions from a typically hypovascularized metastasis of a gastrointestinal tumor.

\section{Special case: Frantz tumor}

The Frantz tumor (solid pseudopapillary neoplasia) is a rare neoplasm of the pancreas, which is seen predominantly in female patients of younger age, down to childhood [97]. This solid pseudopapillary neoplasm does not necessarily cause duct obstruction, and the outlining can be well circumscribed. Cystic degeneration is common. EUS-guided sampling is useful for a preoperative diagnosis [98]. Usually, the operative strategy does not differ from a pancreatic cancer but successful limited resections have also been reported due to more benign behavior and better prognosis of the tumor. Using elastography, the lesions appear hard and in contrast-enhanced EUS (CHI), hypovascularized [99].

\section{Cystic lesions of the pancreas}

Cystic pancreatic lesions are an increasingly common challenge for EUS and other imaging methods. A large variety of different entities can cause cystic pancreatic lesions $[100,101]$. Advantages of EUS for the initial differential diagnosis are the high-resolution investigation of the lesion and the opportunity to perform contrast-enhanced EUS and EUS-FNA. Despite the excellent performance of EUS, it remains impossible to diagnose all different entities correctly. In clinical practice, however, it is safe and pragmatic to classify pancreatic cystic lesions into a few entities with clear conservative or operative strategies. The most common cystic lesions are summarized in Table 1. 
Clinical history from the patient, localization of the lesion in the pancreatic organ, and certain ultrasound criteria may help in characterizing pancreatic cysts. Display of septae and nodules within the cyst may be indicative of (pre-) neoplastic lesions [102]. However, pseudocysts can also show septation, nodules, and wall thickening as well and, thus, can be easily misdiagnosed. A reliable criterion of a neoplastic cystic lesion seems to be the vascularization of the cystic wall, while pseudocysts and common cysts do not have neovascularization of the wall [103]. In color Doppler mode, it is difficult to discriminate vessels of the cystic wall or septae from surrounding vessels. CHI mode seems to be the ideal method in this respect. Due to the excellent resolution, down to a single bubble, and no blooming effect, as in color Doppler mode, cystic wall vascularization can be determined with a high degree of certainty. Thus, it seems to be the perfect method to discriminate (pre-) neoplastic from non-neoplastic cystic lesions [77]. That it is a cystic neoplasm; however, does not necessarily indicate surgical resection. It is well known that serous cystadenomas do not have a very great risk of malignant transformation. Hence, these lesions can be safely watched [104]. The typical honeycomb-like appearance of the microcystic serous cystadenoma does not normally cause differential diagnostic problems; however, the macrocystic or oligocystic type does (Fig. 6) [105]. In those cases, EUS-FNA is helpful in discriminating between a serous cystadenoma and a mucinous cystadenoma.

Another important cystic lesion of the pancreas is the intraductal papillary mucinous neoplasia (IPMN) of the main duct and side branch types. While a malignant transformation of a main-duct IPMN will occur in almost all cases, the malignancy rate of branch-duct IPMNs and of the mucinous cystadenoma is well below $30 \%$ [106]. In small side-branch IPMNs with no highrisk stigmata, according to the International Consensus Guideline (in particular, mural nodules), imaging surveillance can be recommended, in contrast to the operative strategy in patients with main-duct IPMN, branchduct IPMN with high-risk stigmata, and mucinous cystadenoma [107]. Contrast-enhanced EUS is very accurate for the differentiation of definitive mural nodules from mucin clots and, thus, helps to predict the risk of malignancy [108-114]. Elastography does not contribute to the diagnosis of cystic pancreatic lesions.

\section{What is really new?}

Contrast-enhanced EUS is a useful tool for the differentiation of hypovascular pancreatic ductal adenocarcinoma from neuroendocrine tumors and a variety of other solid pancreatic masses, particularly in small solid pancreatic lesions. Moreover, it is of high diagnostic value for the differential diagnosis and risk assessment of pancreatic cystic lesions.

\section{Endoscopic ultrasound of lymph nodes}

The diagnostic value of EUS of mediastinal and abdominal lymph nodes depends on the clinical question $[115,116]$. It should be kept in mind that there are certain regions where physiological lymph nodes measure up to $2 \mathrm{~cm}$ [117]. Common regions are the subcarinal lymph nodes of the mediastinum [115-119] and the lymph nodes in the area of the hepatoduodenal ligament [120-125]. These physiological lymph nodes can mislead staging of the upper gastrointestinal tract. A basic rule can be applied that all lymph nodes close to the tumor should be

Table 1. Overview of common cystic pancreatic lesions for daily practice

\begin{tabular}{|c|c|c|c|c|c|c|c|}
\hline Type & Age, yr & Sex & Localization & $\begin{array}{c}\text { Malignant } \\
\text { potential }\end{array}$ & $\begin{array}{l}\text { Duct com- } \\
\text { munication }\end{array}$ & $\begin{array}{c}\text { Amylase } \\
\text { content }\end{array}$ & CEA \\
\hline Common retention cyst & - & - & Pancreatic head & Non & Seldom & & \\
\hline Pseudocyst & - & - & Variable & Non & Often & +++ & - \\
\hline Serous cyst adenoma & $>60$ & $\mathrm{~F}>\mathrm{M}$ & - & Very low & Seldom & - & - \\
\hline Mucinous cyst adenoma & $40-60$ & $\mathrm{~F}>\mathrm{M}$ & Pancreatic body or tail & Moderate & Rare & - & ++ \\
\hline IPMN & $60-70$ & $\mathrm{M}>\mathrm{F}$ & Pancreatic head & Moderate to high & Typical & ++ & ++ \\
\hline Solid pseudopapillary neoplasia & $20-40$ & $\mathrm{~F}>\mathrm{M}$ & - & Moderate & Seldom & & \\
\hline
\end{tabular}

CEA, carcinoembryonic antigen; IPMN, intrapancreatic papillary mucinous neoplasia. 

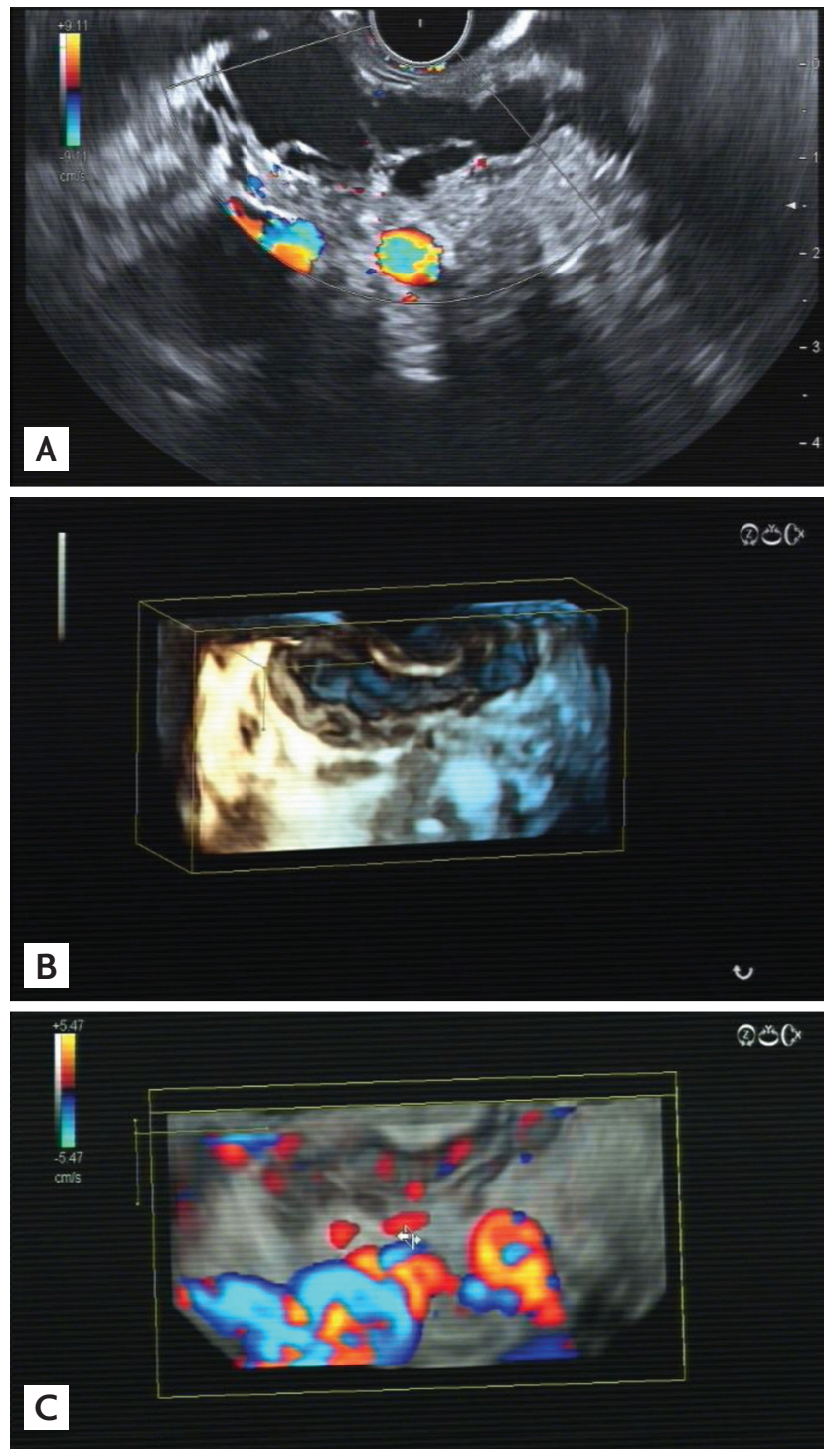

Figure 6. (A) Macrocystic serous cystadenoma of the pancreatic body in B-mode: cystic tumor with multiple septae and with no neoplastic nodule. (B) Three-dimensional (3D) reconstruction of the lesion using contrast harmonic imaging mode after injection of $4.8 \mathrm{~mL}$ Sonovue (Bracco) displays well the vascularization of the septae. (C) With 3D reconstruction of B-mode and color Doppler mode, the macrovessels of the lesion are visible. The close relation to the splenic vein on the left lower side (blue coding) is nicely displayed.

considered malignant and every adjacent lymph node area and the lymph nodes in between are pathological as well [126]. This means that subcarinal lymph nodes of the mediastinum can be neglected in the staging of a gastric cancer so long as the lower mediastinal lymph nodes in stations 9 and 10 are not enlarged.

This level of uncertainty indicates that criteria for ma- lignant and benign lymph nodes other than size should be developed. There are B-mode criteria for the discrimination of malignant and benign lymph node enlargements. A typical benign lymph node is polygonal, not sharply delineated, and with an intact hilar region. A typical malignant lymph node is round, sharply delineated, and does not have a clear hilus region [127]. Unfortunately, those criteria are only true in 50\% to $60 \%$ of cases and, thus, not reliable in clinical practice. Color Doppler criteria have been investigated. A typical benign lymph node shows an outward-pointing vascularization from the lymph node hilus, whereas a malignant lymph node shows capsule vessels pointing inwards [128]. Again, those criteria are not reliable and are, thus, not used in clinical practice. Subsequently, modern endosonographic methods have been studied to improve the discrimination of benign and malignant lymph nodes. To date, there have been many studies of elastography and contrast-enhanced EUS on that topic [15,116,129,130]. So far, the results are inconsistent and should be viewed critically. In contrast studies, it is assumed that areas with poor perfusion are malignant because of the hypovascularization of most common gastrointestinal tumors. Other studies have analyzed the Doppler sonographic criteria of malignant neovascularization. All studies, however, have ignored the fact that a lymph node is an organ with malignant metastasis and, thus, is not always completely infiltrated. A nest of a few tumor cells is enough for a pathologist to histologically stage a lymph node as malignant. Those nests of micrometastasis can be so small that they remain easily below the detection level of contrast-enhanced EUS. Those malignant lymph nodes appear unchanged in morphology and do not show changes, even with the help of modern EUS techniques. However, even if an area of poor vascularization can be detected within a lymph node, it does not necessarily indicate malignancy. A well-known reason for focal poor vascularization is a necrotic area of the lymph node, for example, in patients with tuberculosis [131]. Another pitfall is lymph node infiltration by a malignant lymphoma. Those lymph nodes are highly vascularized and the hilum is normally unchanged [131]. Such indicators resulted in a vote on the part of the EFSUMB not to recommend contrast-enhanced ultrasound for the discrimination of malignant and benign lymph nodes, despite current evidence in the literature [71]. 
Elastography seems to be more promising. Differences in hardness of areas of the lymph node are more reliable regarding malignant areas and, thus, could be used for targeting a biopsy needle [87,132]. An interesting approach for improving elastographic results is the use of automatic analysis software systems that may be able to spot subtle differences the human eye is not able to detect $[116,133]$.

What is really new?

Guidelines suggest the use of elastography to improve targeting of the most suspicious lymph nodes and areas within lymph nodes.

\section{Endoscopic ultrasound of the rectum}

The main indication for EUS of the rectum is the staging of rectal cancer. Initially, only stiff ultrasound probes were used; however, more flexible probes are taking over because of easier handling and the same quality of ultrasound images [134]. A disadvantage of flexible ultrasound probes, however, is the less reliable measurement of the distance between the anal verge and beginning of a rectal tumor.

The aim of the EUS for staging of rectal tumors is the same as that in the upper gastrointestinal tract. Early tumors, possibly suitable for endoscopic resection, should be distinguished from tumors that will require surgery. In the surgical group, tumors that can be resected immediately should be separated from tumors that will need neoadjuvant treatment. According to a recent meta-analysis, MRI, CT, and EUS yielded similar accuracy in staging of rectal cancer, but were outperformed by high-resolution MRI and 3.oT-MRI (Siemens, Erlangen, Germany) [135].

In advanced stages, the involvement of the perirectal fascia may be of prognostic importance. To date, it was assumed that its involvement could only be assessed with MRI, but newer studies have shown that EUS can also detect infiltration of the perirectal fascia [136].

What is really new?

Assessment of the perirectal fascia should be included in EUS staging of rectal cancer.

\section{Endoscopic ultrasound of the anus}

EUS is also the method of choice for the staging of anal cancer because of its high resolution [137-139]. Overall, benign diseases are much more often the reason for requesting EUS of the anus than malignant diseases. Quite often, EUS has been used for the diagnosis of fistulas and abscesses, especially in patients with Crohn's disease [140-142]. Another important indication is the differential diagnosis of incontinence, because of the highresolution display of the inner and outer anal muscle system [143]. In woman, most defects of the muscle system are caused peripartally but become symptomatic in older age as the compensatory effects of the surrounding muscles disappear. EUS plays a major role in planning operative anal repair [144].

\section{SEMI-INVASIVE DIAGNOSTIC ENDOSCOPIC UL- TRASOUND}

The invention of the longitudinal ultrasound probe enabled EUS-guided needle biopsies of surrounding tissues in the upper and lower gastrointestinal tract. Special needle systems for the long working channel of the instrument had to be invented. One of the systems, the Hancke-Vilman needle, became well known, and the principle of this first needle system is still applied today [145].

Today, many needle systems are available with further improvements in design for collecting sufficient material [146]. Today four different needle sizes are used commonly: 19-G needles (aspiration and core biopsy), 20-G (core biopsy), 22-G (standard size, aspiration, and core biopsy), and ultrathin $25-\mathrm{G}$ needles. The Tru-cut needle, developed for obtaining tissue cylinders for histology, does not play a major role in EUS because of the impaired flexibility and a mechanism that is difficult to handle [147]. Further modern developments with novel designs of the needle tip are intended to collect tissue for histology rather than cytological material. Reverse side-bevel technology near the needle tip, as in the ProCore needle, did not seem to increase the diagnostic yield according to a recent meta-analysis. However, the number of needle passes to obtain diagnostic tissue was reduced using the new core needle [148]. A new variant of the ProCore needle (20 G) was introduced with 
a forward-facing direction of the side bevel. Two newly introduced needles (SharkCore, Medtronic, Dublin, Ireland; and Acquire, Boston Scientific, Natick, MA, USA), are designed with two or three opposing sharp points and a multifaceted bevel in the needle tip, aimed at capturing a core of tissue. In first studies, the histology yield was significantly higher than using standard aspiration needles, and diagnosis was possible with fewer needles passes [149-153].

\section{Collection and handling of material for fine-needle aspiration}

Material for cytopathological analyses is usually collected by a FNA system. Despite the similar results of all needle sizes in studies, it is important to stress that larger needle diameters can provide better materials for histology, but smaller needle diameters improve diagnostic material for cytology [72].

The position of the stylet during the procedure had no impact on the final result of the acquired material [154]. The same was true for applying no, little, or strong suction during the aspiration [155]. Even the modern "slow pull" technique, where the stylet is removed slowly during the puncture procedure, had only marginal effects on the quality of the material acquired [156].

Further handling of the material depends on the analysis method used after collecting the material. In the method of choice for a histological investigation, the material should be simply transferred into a formalinfilled vessel by flushing out the needle with air or reinserting the stylet. If the material is going to be analyzed cytologically, the material should be spread on slides and air-dried or alcohol-fixed, according to the staining method to be used.

Whereas Papanicolaou staining requires immediate alcohol fixation of the material, May-Gruenwald staining needs only air-dried samples. If cytology is intended, sucking the material into the vacuum syringe should be avoided because of the difficulty in spreading the material in a thin layer on slides. Another common pitfall is to load all slides with material first and try to spread the material at the end. The drying process starts immediately after the material leaves the needle and cells cannot be spread sufficiently if left too long [72].

Special cleaning methods of the material before cy- tological analysis should also be avoided in endoscopic FNA cytology because of the potential loss of material and the resulting impaired diagnosis $[157,158]$. For preparing a cell block, the aspirated specimen can be placed into liquid medium (Cytolyt, Hologic Inc., Marlborough, MA, USA).

Cytological analysis of the material has the advantage of higher sensitivity than histology [159]. Evaluation of the quality of the material can be made from a few cells, unlike in histology. Another advantage is the good intraobserver variability because of standardized diagnostic criteria [160]. After appropriate training, even endoscopists can pre-analyze the material with a high degree of certainty [161]. This could mark a starting point for the reinvention of clinical cytology. However, this will not replace the need for a professional cytologist (Fig. 7).

Even cytochemistry can be performed on air-dried smears. However, it needs a professional and enthusiastic cytologist to ensure reliable results [162].

Trying to perform histology with the collected material needs special techniques, like the cell-block technique $[163,164]$. Generally, the best results are achieved if the pathologist and endoscopist are working closely together. In principle, the method that is established and works best in the individual hospital should be used.

\section{Cystic lesions}

Every EUS-guided fine-needle puncture is an unsterile puncture of the human body. This is especially important in the puncture of cystic lesions because the esophagus and stomach are not sterile. This can be neglected if the target is solid and perfused, given the multiple defense strategies of the human body [165].

This is different in cystic lesions. Without a blood supply, the cystic fluid is vulnerable to infection and, thus, peri-interventional antibiotic treatment is recommended [166]. Bronchogenic cysts have a high risk of infection despite antibiotic prophylaxis; thus, endoscopic fine-needle puncture is contraindicated [167].

Neoplastic cystic lesions of the pancreas are often targeted for endoscopic FNA. Unfortunately, cytological results are often not helpful and, therefore, physical and biochemical analyses should be performed as well to improve the diagnostic result.

Neoplastic cystic pancreatic lesions differ in their malignant potential according to their pathogenesis. 
Serous cystadenomas have a very low malignancy risk and, therefore, do not require surgery in the first place [168]. In mucinous cystadenoma, the malignant potential is as high as $30 \%$; therefore, surgery is recommended as soon as the diagnosis is established [101,169-171]. A simple estimation of the mucinous appearance of the aspirated fluid as it drops from the tip of the FNA needle in a relevant percentage of mucinous pancreatic cysts seems to be sufficient for an adequate diagnosis. The so-called string sign is highly specific for the diagnosis of mucinous pancreatic cysts [172]. Analysis of the carcinoembryonic antigen (CEA) level in the fluid can add to the diagnosis. Many other markers have been studied. However, to date, no better marker has been found. The

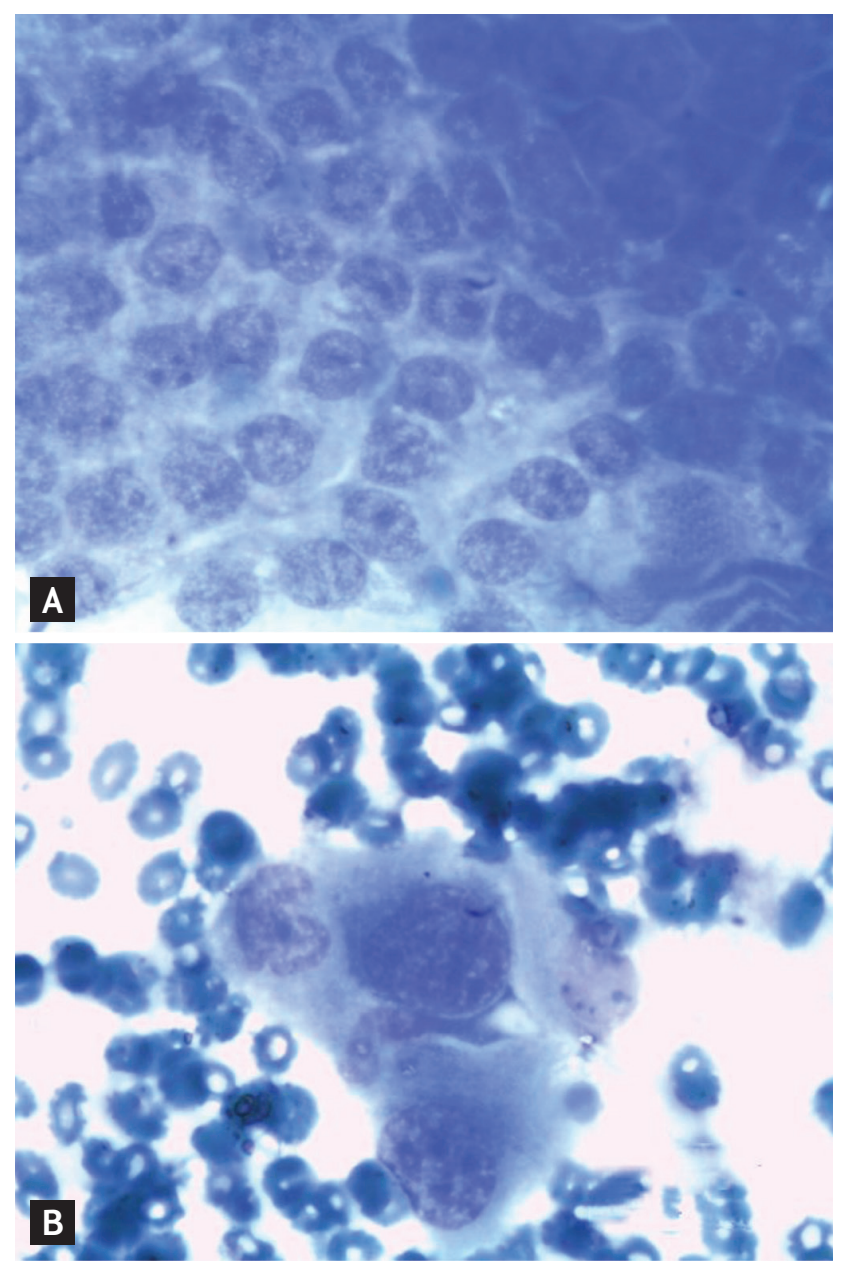

Figure 7. (A) Cytological specimen of normal pancreatic cells after staining with Quikstain: note the homogeneous impression of centrally located nuclei ( $\times 400$, with oil). (B) In contrast, cells of a pancreatic adenocarcinoma (surrounded by erythrocytes) present with inhomogeneous, enlarged, and more peripherally located nuclei (×400, with oil).
CEA level does not correlate with the actual presence of malignancy in the lesion; it only indicates the malignant potential of the lesion and the mucinous nature. CEA is elevated in fluid aspirate from mucinous cystadenomas and IPMNs. There are no standardized CEA levels for discriminating lesions with malignant potential versus no malignant potential. It is fair to assume; however, that levels above 200 to $800 \mathrm{ng} / \mathrm{L}$ should be considered pathological. However, a high lipase level in aspirated cystic fluid can be considered a sign of a low malignant potential $[173,174]$. A sequential cyst fluid interpretation including string sign, CEA, and cytology was shown to have an increased overall accuracy of $>90 \%$ for the diagnosis of mucinous pancreatic cysts compared with individual tests alone [172,175]. Molecular analysis of cyst fluid is an emerging technique. However, published data do not yet support its routine use [176-178]. A recent meta-analysis showed that neither KRAS (Kirsten rat sarcoma 2 viral oncogene homolog) nor GNAS (guanine nucleotide binding protein, alpha stimulating) mutations were linked with malignant potential or outcome in patients with intraductal papillary-mucinous neoplasia [179].

Not every pancreatic cyst has to be punctured diagnostically. Cysts smaller than $2 \mathrm{~cm}$ mostly do not provide appropriate material for a differential diagnosis and the risk of malignancy is smaller than the morbidity and mortality of a pancreas resection [180,181]. Those lesions should undergo imaging surveillance but should be referred for surgery if there is a change of size or appearance [101].

\section{Diagnosis of subepithelial lesions}

FNA of subepithelial lesions is often not required because small lesions can be characterized by diagnostic EUS and larger subepithelial lesions $(\geq 3 \mathrm{~cm})$ are typically referred directly for surgery $[32,72]$. Thus, FNA is mainly suggested for subepithelial lesions of a size between 1 and $3 \mathrm{~cm}$. Contrast-enhanced EUS was not valuable for targeting non-necrotic areas, especially in large GISTs [32].

Hard lesions with mobile fixation can present technical challenges that can often result in disappointing cytological and histological material [22]. However, typical GISTs have loose cell connections and are soft, resulting in better diagnostic material. Prognostic criteria 
for malignant behavior in GISTs are based on the size, the organ, the mitotic count in a high-power field and immuno(histo)chemistry. Diagnostic material obtained from FNA should allow immunohistochemistry to distinguish GISTs, leiomyomas, and Schwannomas, and other rare entities [31,182]. A new core needle showed superior diagnostic yield, compared with a standard aspiration needle, for acquiring material suitable for the immunohistochemical differentiation of benign subepithelial gastrointestinal tumors from potentially malignant GISTs [153].

\section{Diagnosis of pathological lymph nodes}

Endosonographic FNA of pathological lymph nodes can be helpful in various clinical situations [117]. One indication is the diagnosis of an enlarged lymph node at a distance from a known tumor. Biopsying a lymph node through an area of a tumor should be carefully avoided because of the risk of false-positive results and needle track seeding [183]. This clinical situation is rather uncommon in gastrointestinal tumors, but is common for pulmonological tumors $[117,119]$. The development of endobronchial endoscopic ultrasound (EBUS) in combination with transesophageal ultrasound made the previously often performed mediastinoscopy nearly obsolete [184]. We refer to the recently described methods of endobronchial elastography $[13,89,116,118]$ and contrast enhanced EBUS [12,185].

Especially in indeterminate pulmonary lesions, endosonographic FNA can help to diagnose tumors with lymph node involvement if they cannot be reached directly by bronchoscopy. Non-small cell carcinoma and small cell carcinoma can be distinguished readily by FNA of involved lymph nodes [186]. The resulting material can even be used for further testing, such as EGF (epidermal growth factor) receptor analysis, for a more targeted therapy [187].

Another not uncommon clinical situation is the presence of enlarged mediastinal and abdominal lymph nodes without peripheral lymph node enlargement $[13,116,130]$. In such situations, an endosonographic FNA can be diagnostic leading, but still might not enable a final diagnosis [188]. For example, it is possible to identify epitheloid granulomas as a sign of sarcoidosis [189]. Cytology or cell-block techniques can even diagnose a highly malignant lymphoma reliably. Studies are underway to show that cytological results can correctly diagnose lymphoma without the need for a histological assessment of a whole lymph node [190].

With appropriate preparation and handling of the specimen, even lymph node involvement by tuberculosis can be diagnosed. If the material is handled correctly, the specimen can be used for bacterial cultivation and even resistance testing. This is of the utmost importance in cases of isolated lymph node tuberculosis [191,192].

\section{Uncommon targets}

Other targets are the left adrenal gland [193,194], the liver [195], and the spleen [196]. The most common indication of a puncture of the left adrenal gland is the diagnosis of a metastasis of a bronchial carcinoma [117,119]. Incidentalomas of the left adrenal gland rarely need a diagnostic puncture [197]. Hormone-active tumors do not need cytological or histological confirmation, due to the typical clinical appearance and laboratory findings $[198,199]$. If a suspected pheochromocytoma requires confirmation by EUS-FNA, premedication should be given to avoid a hypertensive crisis [200].

Liver and splenic lesions are easy to target if they are near the ultrasound probe. The risk of bleeding is regarded as low. The procedure is especially recommended in lesions that are very small and hard to reach percutaneously [201-203].

Sometimes, there is the possibility of accessing a lung cancer from the esophagus if it is located close enough. The risk is comparable to a bronchoscopic puncture; the complication rate may even be lower due to the direct needle guidance and excellent needle visualization [117$119,184,185,204]$.

\section{What is really new?}

New needles have been developed, aimed at core biopsies, potentially improving the minimally invasive diagnosis of specific types of neoplasms (e.g., mesenchymal gastrointestinal tumors and lymphomas) and inflammation (e.g., autoimmune pancreatitis), where tissue architecture, immunohistochemistry, and the evaluation of molecular marker expression is necessary for diagnosis, grading, subtyping, and guiding personalized therapy. For EUS-FNA of cystic pancreatic lesions, a multimodal diagnostic approach to cyst fluid analysis (string sign, biochemistry, cytology, and perhaps molecular analysis) 
can help to improve the accuracy of pancreatic cyst diagnosis and risk assessment.

\section{THERAPEUTIC EUS APPLICATIONS}

\section{Endosonographic-guided ablation therapy and implan- tation of diagnostic material (fiducial placement)}

The visibility and the ability to guide the tip of the needle exactly makes EUS ideal for targeting lesions in ablative interventions. The most commonly practiced procedure is EUS-guided plexus neurolysis [74]. The principle of the procedure is to inject $96 \%$ alcohol into the area of the celiac trunk to destroy the celiac plexus. Modern endosonographic probes can even visualize the small plexus ganglia. If possible, the alcohol should be injected directly into the visible ganglia. Unfortunately, the reported clinical results are inconsistent. Typically, the patient's pain is eased after the procedure but does not resolve completely [205]. Serious side-effects, like abscess development or erosion of the aorta with lethal bleeding, have been reported and, thus, it is necessary, always, to strictly control the indication $[165,206]$.

The thought of destroying tissue by alcohol injection was taken forward for tumor ablation in inoperable patients [207]. Especially in older patients with symptomatic neuroendocrine tumors of the pancreas, this method seems to be an alternative to a pancreatic resection. This method was first successfully reported by Jurgensen et al. [208].

Other studies have dealt with alcohol and chemotherapeutic ablation of cystic tumors of the pancreas [209]. The overall success rates have been acceptable; however, the indication of tissue ablation has to be considered critically because of the uncertain diagnosis of the cystic pancreatic lesions without histology. It seems likely that a considerable proportion of patients in these studies received an overtreatment [210,211].

Another emerging application of EUS is the placement of internal markers, called fiducials. Implantable fiducial markers provide a highly effective method of ensuring accurate targeting in surgery or radiotherapy. In view of the poor prognosis of pancreatic cancer, surgery remains the only curative option. Locally advanced pancreatic cancers cannot be operated on in the first place but might become resectable after neoadjuvant treat- ment. Various concepts of neoadjuvant treatments are under investigation, including radiotherapy. Unfortunately, radiotherapy of the abdomen has a considerable risk of side effects; therefore, the radiation field should be as focused as possible. The endosonographic placement of fiducials as reference points around the tumor can help the radiotherapist to plan the radiotherapy optimally. Systems for implantation of fiducials are mostly improvised. One feasible option is to use a 19-G needle loaded with multiple fiducials while the needle tip is sealed using bone wax to prevent the fiducials from slipping out of the needle prematurely. The needle can then be placed in the precise position marking the target and the fiducial can be released by stylet re-insertion [212].

\section{Interventional endosonographic drainage proce- dures}

Endosonographic interventions emerged when surgical strategies in the management of severe acute pancreatitis were questioned. A feared complication of acute necrotizing pancreatitis is the superinfection of the resulting walled-off necrosis. The standard treatment 20 years ago was open surgery with repeated wound debridement. The mortality of this strategy was high and a major breakthrough came with the recognition that patients with a limited intervention recovered better than patients undergoing major surgery [213]. An endoscopic approach, inserting drains into the necrotic cavities through the stomach or duodenal wall, worked in some patients, but the breakthrough came with the EUS-guided creation of large diameter transmural access that allowed direct visualization of the walled-off necrosis and endoscopic debridement [214,215]. The principle of the initially described procedure is still the same today. The walled-off necrosis is accessed from the stomach or duodenum using a 19-G needle or cystotome under endosonographic guidance before a guidewire is introduced for the Seldinger technique. The newly created transgastric or transduodenal access can be enlarged using bougies, diathermy (cystotomes), or balloon catheters up to a diameter of 8 to $12 \mathrm{~mm}$. The resulting orifice in the gastric or duodenal wall should be secured by plastic pigtail drainages or specially designed, fully covered metal stents for pancreatic drainage [75,216]. Further developments have aimed at a one-step procedure $[214,217,218]$. Today, a simplified approach for the inser- 
tion of a covered metal stent is about to take over. This one-step equipment can be handled safely and does not necessarily need X-rays for guidewire control [217-219]. In infected walled-off necrosis with large amounts of debris, a simple drainage procedure is not sufficient for complete healing and resolving the fluid collection; even large- diameter stents can become blocked by solid necrotic material. If the diameter of the inserted metal stent is large enough (>12 $\mathrm{mm}$ ) a standard gastroscope can be advanced through the stent into the infected necrotic cavity. This allows irrigation and sucking of pus under endoscopic control and removing loose necrotic tissue. Wall-fixed necrosis should not be removed forcefully because of the risk of severe bleeding (Fig. 8) [220]. The EFSUMB guideline [221] covers all aspects of interventional EUS and is highly recommended [72-75,222229].

Plastic or metal stents used for drainage should be removed after the collection has resolved, to enable secondary wound healing. The drain should be removed af ter about 4 weeks, but in cases of covered metal stents, at the latest, after 12 weeks, to avoid tissue ingrowth, which may hinder the removal [75].

The principle of the Seldinger technique for drainage purposes in EUS has been applied to other indications [230]. One possible indication is the treatment of cholestasis if endoscopic retrograde cholangiopancreatography (ERCP) is technically not possible and percutaneous transhepatic cholangiodrainage (PTCD) is not feasible. Introducing a guidewire into the bile system after EUS-guided puncture of a bile duct enables rendezvous procedures with ERCP or direct drainage over the puncture side. For direct drainage, plastic stents can be placed; however, more and more often fully covered metal stents are used [231]. Two recent meta-analyses of studies and case series of endosonography guided biliary drainage reported cumulative technical success rates of $90 \%$ and $95 \%$, a clinical success rate of $92 \%$, and cumulative adverse event rates of $17 \%$ and $23 \%$, respectively [232,233]. Extrahepatic access seems to be safer than intrahepatic access [232]. Compared with PTCD, endosonography guided biliary drainage has the same technical success rate, and a higher clinical success rate, but significantly fewer complications, and a lower rate of unplanned re-interventions [234,235].

One simple procedure is the so-called short rendez- vous. In this, the common bile duct is punctured under endosonographic guidance in the area of the duodenal bulb and the introduced guidewire is advanced further through the papilla into the duodenum. After removing the ultrasound probe with the guidewire still in place, a standard side-viewing endoscope has to be introduced and the floppy end of the guidewire is caught using forceps or a snare and pulled through the endoscopeworking channel. Then, it is used as a normal guidewire for ERCP, providing transpapillary access [236].

In special clinical situations, such as cholecystitis in patients unfit for surgery, even an internal transgastric drainage of the gallbladder can be performed. In those situations, lumen-apposing drainage systems should be used to avoid biliary peritonitis [237]. Recent studies show a high success rate with fewer adverse events and fewer repeat procedures than percutaneous cholecystotomy [238-240].

In principle, all the procedures described above for duct drainage can also be applied to drainage of the pancreatic duct. For draining the pancreatic duct, there is no minimal invasive alternative available, such as PTCD for bile duct drainage. If the pancreatic duct is disconnected after trauma or severe pancreatitis, the feasibility of EUS-guided stenting of the distal pancreatic duct should be considered [241-243]. However, EUS-guided drainage of the pancreatic duct requires the highest technical skill because of the hard and partly calcified pancreatic tissue and the small diameter duct, which limits the space for any intervention. The failure rate is higher than $10 \%$. In addition, an unsuccessful procedure can cause complications of severe acute pancreatitis [242-244].

\section{What is really new?}

With the development of new devices and stents, endosonography-guided drainage techniques have gained clinical importance as effective alternatives to surgical and endoscopic procedures. While EUS-guided drainage of (peri-)pancreatic fluid collections and necroses is now fully accepted as a first-line therapeutic technique, EUS-guided drainage of obstructed bile ducts and acute cholecystitis is moving into daily clinical practice. 


\section{FUTURE PERSPECTIVES}

EUS has seen the biggest technical and diagnostic advances of all gastroenterological methods in recent years. In a short time, new technologies like elastography $[87,132]$ and contrast-enhanced EUS [245], and interventional methods, like endoscopic necrosectomy of the pancreas and biliary drainage, could be introduced into daily clinical practice.

Novel methods like three-dimensional (3D) EUS are emerging. Such further post-processing of the ultrasound information can produce impressive results [55]. To date, the biggest limitation of $3 \mathrm{D}$ methods is the freehand technique, which does not allow measurements of the lesion of interest. New diagnostic fields could be explored if measurements become possible. We hope that 3D techniques might detect an early response to chemotherapy and might help to avoid unnecessary treatments [246,247].

Multiple treatment studies have been introduced to treat pancreatic cancer with virus vectors. EUS worked as a precise instrument for the placement of these viruses directly into the tumor. Unfortunately, this interesting technique has not yet reached clinical practice [248].

A very promising field is molecular imaging. Tumor detection and delineation could become more sensitive with antibody-loaded contrast-enhancer bubbles. This kind of red flag technique would increase the diagnostic potential of the method greatly. Contrast-enhanced ultrasound has the advantage of requiring only a small amount of contrast enhancer for an adequate visualization compared with CT or MRI techniques [249].

More interesting would be the use of contrast bubbles as carriers for medications. The possibility of destroying contrast bubbles with the help of ultrasound energy in the area of ultrasound scanning makes the method attractive. EUS would be a perfect device due to the small transducer and the close position to the pancreas or other upper gastrointestinal tract-surrounding organs. Studies using percutaneous ultrasound and so-called sonoporation have shown promising results $[250,251]$.

Regarding interventional EUS, further improvements in drainage techniques are on the horizon. Technically demanding techniques, like EUS-guided gastroenterostomy, are promising and perhaps in future may be considered alternatives to surgical bypass techniques and
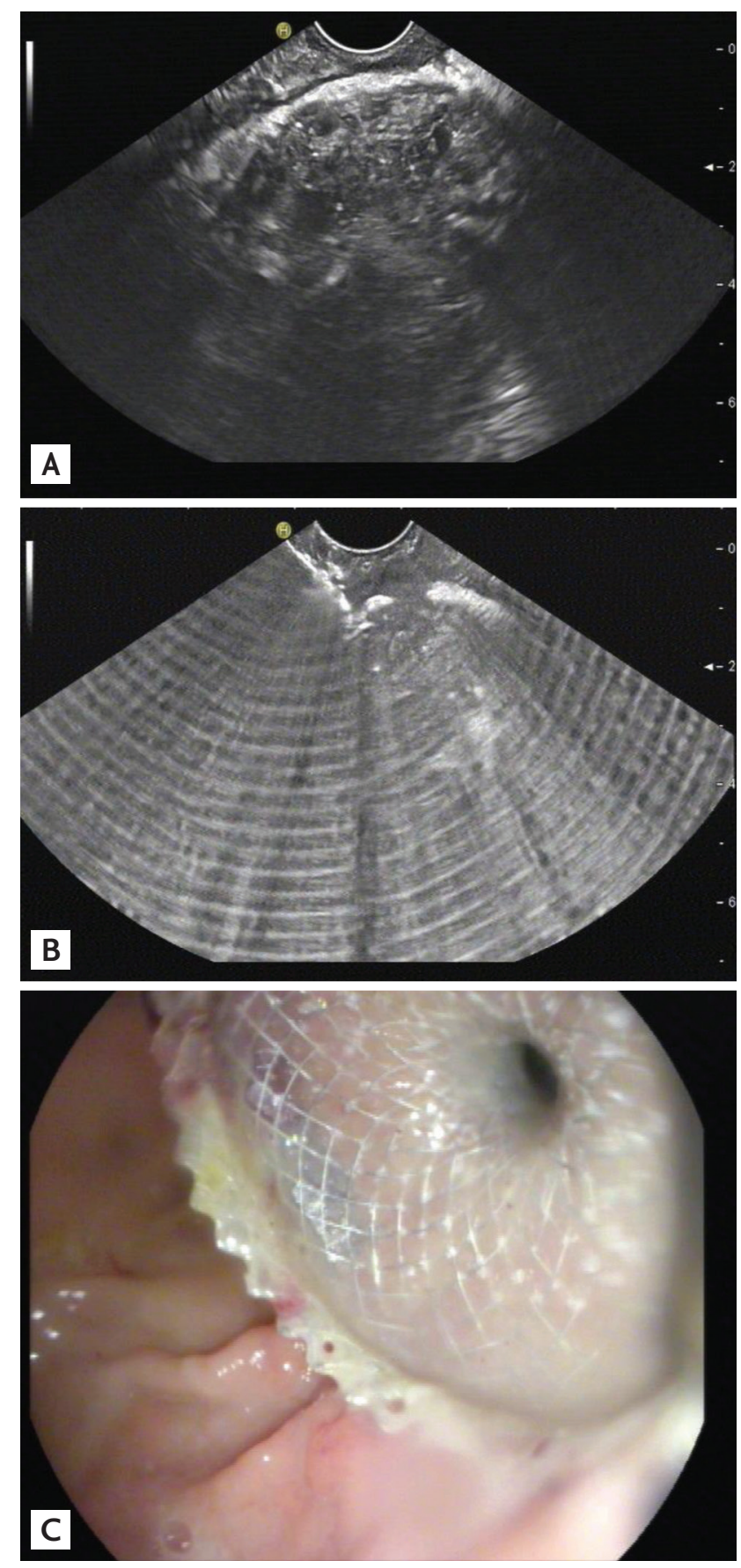

Figure 8. (A) Pancreatic abscess in B-mode. (B) Hyperechoic artifacts induced by diathermic penetration of the stomach wall. (C) Outflow of pus into the gastric lumen after transmural placement of a fully covered lumen-apposing metal stent.

enteral stenting in cases of malignant gastric outlet obstruction or as a bariatric intervention in patients with morbid obesity [252-255]. 


\section{CONCLUSIONS}

Endoscopic ultrasound has emerged as an indispensable innovative tool providing solutions for many clinical questions. No other method provides so much potential for diagnostic and therapy of gastrointestinal diseases. The available technique is astonishing advanced, and with the introduction of contrast-enhanced techniques and elastography endoscopic ultrasound has improved non-invasive tissue characterization. Endoscopic ultrasound-guided fine-needle aspiration has generated a paradigm shift in tissue diagnosis and oncological staging. Endoscopic ultrasound-guided treatment procedures facilitate transmural access to fluid collections, obstructed ducts, celiac ganglia, tumors, and bleeding vessels. Profound knowledge of all facets of endoscopic ultrasound and solid experience in those techniques are mandatory to use the method to its full capacity.

\section{Conflict of interest}

No potential conflict of interest relevant to this article was reported.

\section{REFERENCES}

1. Moehler M, Galle PR, Kiesslich R. Endosonography of the gastrointestinal tract. Chirurg 2007;78:420-427.

2. Jenssen C, Dietrich CF, Burmester E. Malignant neoplasias of the gastrointestinal tract: endosonographic staging revisited. Z Gastroenterol 2011;49:357-368.

3. Dietrich CF, Jenssen C. Evidence based endoscopic ultrasound. Z Gastroenterol 2011;49:599-621.

4. Mocellin S, Pasquali S. Diagnostic accuracy of endoscopic ultrasonography (EUS) for the preoperative locoregional staging of primary gastric cancer. Cochrane Database Syst Rev 2015;(2):CDoo9944.

5. Moehler M, Baltin CT, Ebert M, et al. International comparison of the German evidence-based S3-guidelines on the diagnosis and multimodal treatment of early and locally advanced gastric cancer, including adenocarcinoma of the lower esophagus. Gastric Cancer 2015;18:550-563.

6. Watari J, Ueyama S, Tomita T, et al. What types of early gastric cancer are indicated for endoscopic ultrasonography staging of invasion depth? World J Gastrointest Endosc 2016;8:558-567.
7. Talsma K, van Hagen P, Grotenhuis BA, et al. Comparison of the 6th and 7 th editions of the UICC-AJCC TNM classification for esophageal cancer. Ann Surg Oncol 2012;19:2142-2148.

8. Jurgensen C, Brand J, Nothnagel M, et al. Prognostic relevance of gastric cancer staging by endoscopic ultrasound. Surg Endosc 2013;27:1124-1129.

9. Foley KG, Lewis WG, Fielding P, et al. N-staging of oesophageal and junctional carcinoma: is there still a role for EUS in patients staged No at PET/CT? Clin Radiol 2014;69:959-964.

10. Wee E, Lakhtakia S, Gupta R, et al. The diagnostic accuracy and strength of agreement between endoscopic ultrasound and histopathology in the staging of ampullary tumors. Indian J Gastroenterol 2012;31:324-332.

11. Ignee A, Atkinson NS, Schuessler G, Dietrich CF. Ultrasound contrast agents. Endosc Ultrasound 2016;5:355-362.

12. Fusaroli P, Saftoiu A, Dietrich CF. Contrast-enhanced endoscopic ultrasound: why do we need it? A foreword. Endosc Ultrasound 2016;5:349-350.

13. Cui XW, Chang JM, Kan QC, Chiorean L, Ignee A, Dietrich CF. Endoscopic ultrasound elastography: current status and future perspectives. World J Gastroenterol 2015;21:13212-13224.

14. Larsen MH, Fristrup C, Hansen TP, Hovendal CP, Mortensen MB. Endoscopic ultrasound, endoscopic sonoelastography, and strain ratio evaluation of lymph nodes with histology as gold standard. Endoscopy 2012;44:759-766.

15. Paterson S, Duthie F, Stanley AJ. Endoscopic ultrasoundguided elastography in the nodal staging of oesophageal cancer. World J Gastroenterol 2012;18:889-895.

16. Knabe M, Gunter E, Ell C, Pech O. Can EUS elastography improve lymph node staging in esophageal cancer? Surg Endosc 2013;27:1196-1202.

17. Will U, Zinsser E, Raabe G, Bosseckert H. Value of endosonography in diagnosis of diffusely growing stomach carcinomas. Z Gastroenterol 1998;36:151-157.

18. Will U, Muller AK, Fueldner F, Wanzar I, Meyer F. Endoscopic papillectomy: data of a prospective observational study. World J Gastroenterol 2013;19:4316-4324.

19. Tsuji S, Doyama H, Tsuji K, et al. Preoperative endoscopic diagnosis of superficial non-ampullary duodenal epithelial tumors, including magnifying endoscopy. World J Gastroenterol 2015;21:11832-11841.

20. Nikolaidis P, Hammond NA, Day K, et al. Imaging fea- 
tures of benign and malignant ampullary and periampullary lesions. Radiographics 2014;34:624-641.

21. Guo J, Liu Z, Sun S, et al. Endosonography-assisted diagnosis and therapy of gastrointestinal submucosal tumors. Endosc Ultrasound 2013;2:125-133.

22. Jenssen C, Dietrich CF. Endoscopic ultrasound of gastrointestinal subepithelial lesions. Ultraschall Med 2008;29:236-256.

23. Gress F, Schmitt C, Savides T, et al. Interobserver agreement for EUS in the evaluation and diagnosis of submucosal masses. Gastrointest Endosc 2001;53:71-76.

24. Sonthalia N, Jain SS, Surude RG, Mohite AR, Rathi PM. Congenital esophageal duplication cyst: a rare cause of dysphagia in an adult. Gastroenterology Res 2016;9:79-82.

25. Okanobu H, Hata J, Haruma K, et al. A classification system of echogenicity for gastrointestinal neoplasms. Digestion 2005;72:8-12.

26. Kannengiesser K, Mahlke R, Petersen F, et al. Contrastenhanced harmonic endoscopic ultrasound is able to discriminate benign submucosal lesions from gastrointestinal stromal tumors. Scand J Gastroenterol 2012;47:15151520.

27. Eckardt AJ, Jenssen C. Current endoscopic ultrasoundguided approach to incidental subepithelial lesions: optimal or optional? Ann Gastroenterol 2015;28:160-172.

28. Zhang XC, Li QL, Yu YF, et al. Diagnostic efficacy of endoscopic ultrasound-guided needle sampling for upper gastrointestinal subepithelial lesions: a meta-analysis. Surg Endosc 2016;30:2431-2441.

29. Yamashita Y, Kato J, Ueda K, et al. Contrast-enhanced endoscopic ultrasonography can predict a higher malignant potential of gastrointestinal stromal tumors by visualizing large newly formed vessels. J Clin Ultrasound 2015;43:89-97.

30. Tsuji Y, Kusano C, Gotoda T, et al. Diagnostic potential of endoscopic ultrasonography-elastography for gastric submucosal tumors: a pilot study. Dig Endosc 2016;28:173178.

31. Ignee A, Jenssen C, Hocke M, et al. Contrast-enhanced (endoscopic) ultrasound and endoscopic ultrasound elastography in gastrointestinal stromal tumors. Endosc Ultrasound 2017;6:55-60.

32. Dietrich CF, Jenssen C, Hocke M, Cui XW, Woenckhaus $\mathrm{M}$, Ignee A. Imaging of gastrointestinal stromal tumours with modern ultrasound techniques: a pictorial essay. Z Gastroenterol 2012;50:457-467.
33. Kamata K, Takenaka M, Kitano M, et al. Contrast-enhanced harmonic endoscopic ultrasonography for differential diagnosis of submucosal tumors of the upper gastrointestinal tract. J Gastroenterol Hepatol 2017;32:16861692.

34. Sakamoto H, Kitano M, Matsui S, et al. Estimation of malignant potential of GI stromal tumors by contrastenhanced harmonic EUS (with videos). Gastrointest Endosc 2011;73:227-237.

35. Park HY, Jeon SW, Lee HS, et al. Can contrast-enhanced harmonic endosonography predict malignancy risk in gastrointestinal subepithelial tumors? Endosc Ultrasound 2016;5:384-389.

36. Lim TW, Choi CW, Kang DH, Kim HW, Park SB, Kim SJ. Endoscopic ultrasound without tissue acquisition has poor accuracy for diagnosing gastric subepithelial tumors. Medicine (Baltimore) 2016;95:e5246.

37. Lin M, Fu Y, Yu H, Huang J. Gastric heterotopic pancreas masquerading as a stromal tumor: a case report. Oncol Lett 2015;10:2355-2358.

38. Pouessel G, Michaud L, Pierre MH, et al. Endoscopic diagnosis of a gastric heterotopic pancreas and esophageal atresia: an incidental association? Arch Pediatr 2001;8:181185.

39. Bennett S, Lam M, Wasserman J, et al. A case series of two glomus tumors of the gastrointestinal tract. J Surg Case Rep 2015;2015:rju144. https://doi.org/10.1093/jscr/rju144.

40. Jeon TJ, Cho JH, Kim YS, Song SY, Park JY. Diagnostic value of endoscopic ultrasonography in symptomatic patients with high and intermediate probabilities of common bile duct stones and a negative computed tomography scan. Gut Liver 2017;11:290-297.

41. Seifert H, Wehrmann T, Hilgers R, Gouder S, Braden B, Dietrich CF. Catheter probe extraductal EUS reliably detects distal common bile duct abnormalities. Gastrointest Endosc 2004;60:61-67.

42. Deprez P. Approach of suspected common bile duct stones: endoscopic ultrasonography. Acta Gastroenterol Belg 2000;63:295-298.

43. Cremer A, Arvanitakis M. Diagnosis and management of bile stone disease and its complications. Minerva Gastroenterol Dietol 2016;62:103-129.

44. Park JG, Kim KB, Han JH, et al. The usefulness of early endoscopic ultrasonography in acute biliary pancreatitis with undetectable choledocholithiasis on multidetector computed tomography. Korean J Gastroenterol 
2016;68:202-209.

45. Fabbri C, Polifemo AM, Luigiano C, et al. Single session versus separate session endoscopic ultrasonography plus endoscopic retrograde cholangiography in patients with low to moderate risk for choledocholithiasis. J Gastroenterol Hepatol 2009;24:1107-1112.

46. Cui XW, Ignee A, Braden B, Woenckhaus M, Dietrich CF. Biliary papillomatosis and new ultrasound imaging modalities. Z Gastroenterol 2012;50:226-231.

47. Jenssen C, Dietrich CF. Endoscopic ultrasound in chronic pancreatitis. Z Gastroenterol 2005;43:737-749.

48. Hernandez LV, Catalano MF. EUS in the diagnosis of early-stage chronic pancreatitis. Best Pract Res Clin Gastroenterol 2010;24:243-249.

49. Dominguez-Munoz JE. Latest advances in chronic pancreatitis. Gastroenterol Hepatol 2014;37 Suppl 3:93-97.

50. Del Pozo D, Poves E, Tabernero S, et al. Conventional versus Rosemont endoscopic ultrasound criteria for chronic pancreatitis: interobserver agreement in same day backto-back procedures. Pancreatology 2012;12:284-287.

51. De Molo C, Cui XW, Pirri C, et al. Pancreas mobile. Z Gastroenterol 2013;51:1165-1170.

52. Omiyale AO. Autoimmune pancreatitis. Gland Surg 2016; 5:318-326.

53. Brito-Zeron P, Bosch X, Ramos-Casals M, Stone JH. IgG4related disease: advances in the diagnosis and treatment. Best Pract Res Clin Rheumatol 2016;30:261-278.

54. Hocke M, Ignee A, Dietrich CF. Contrast-enhanced endoscopic ultrasound in the diagnosis of autoimmune pancreatitis. Endoscopy 2011;43:163-165.

55. Hocke M, Ignee A, Dietrich CF. Three-dimensional contrast-enhanced endoscopic ultrasound for the diagnosis of autoimmune pancreatitis. Endoscopy 2011;43 Suppl 2 UCTN:E381-E382.

56. Saftoiu A, Dietrich CF, Vilmann P. Contrast-enhanced harmonic endoscopic ultrasound. Endoscopy 2012;44:612617.

57. Dietrich CF, Hirche TO, Ott M, Ignee A. Real-time tissue elastography in the diagnosis of autoimmune pancreatitis. Endoscopy 2009;41:718-720.

58. Lopez-Serrano A, Crespo J, Pascual I, et al. Diagnosis, treatment and long-term outcomes of autoimmune pancreatitis in Spain based on the International Consensus Diagnostic Criteria: a multi-centre study. Pancreatology 2016;16:382-390.

59. Sugumar A, Chari S. Autoimmune pancreatitis: an up- date. Expert Rev Gastroenterol Hepatol 2009;3:197-204.

6o. Ishikawa T, Itoh A, Kawashima H, et al. Endoscopic ultrasound-guided fine needle aspiration in the differentiation of type 1 and type 2 autoimmune pancreatitis. World J Gastroenterol 2012;18:3883-3888.

61. Kanno A, Masamune A, Fujishima F, et al. Diagnosis of autoimmune pancreatitis by EUS-guided FNA using a 22-gauge needle: a prospective multicenter study. Gastrointest Endosc 2016;84:797-804.e1.

62. Morishima T, Kawashima H, Ohno E, et al. Prospective multicenter study on the usefulness of EUS-guided FNA biopsy for the diagnosis of autoimmune pancreatitis. Gastrointest Endosc 2016;84:241-248.

63. Sharma M, Pathak A, Rameshbabu CS, Rai P, Kirnake $\mathrm{V}$, Shoukat A. Imaging of pancreas divisum by lineararray endoscopic ultrasonography. Endosc Ultrasound 2016;5:21-29.

64. Rana SS, Bhasin DK, Sharma V, Rao C, Singh K. Role of endoscopic ultrasound in the diagnosis of pancreas divisum. Endosc Ultrasound 2013;2:7-10.

65. Puri R, Manrai M, Thandassery RB, Alfadda AA. Endoscopic ultrasound in the diagnosis and management of carcinoma pancreas. World J Gastrointest Endosc 2016;8:67-76.

66. Dietrich CF, Sahai AV, D'Onofrio M, et al. Differential diagnosis of small solid pancreatic lesions. Gastrointest Endosc 2016;84:933-940.

67. Nakamura T, Masuda K, Harada S, Akioka K, Sako H. Pancreatic cancer: slow progression in the early stages. Int J Surg Case Rep 2013;4:693-696.

68. Hocke M, Schulze E, Gottschalk P, Topalidis T, Dietrich CF. Contrast-enhanced endoscopic ultrasound in discrimination between focal pancreatitis and pancreatic cancer. World J Gastroenterol 2006;12:246-250.

69. Saftoiu A, Vilmann P, Gorunescu F, et al. Accuracy of endoscopic ultrasound elastography used for differential diagnosis of focal pancreatic masses: a multicenter study. Endoscopy 2011;43:596-603.

70. Dietrich CF, Dong Y, Froehlich E, Hocke M. Dynamic contrast-enhanced endoscopic ultrasound: a quantification method. Endosc Ultrasound 2017;6:12-20.

71. Piscaglia F, Nolsoe C, Dietrich CF, et al. The EFSUMB guidelines and recommendations on the clinical practice of contrast enhanced ultrasound (CEUS): update 2011 on non-hepatic applications. Ultraschall Med 2012;33:33-59.

72. Jenssen C, Hocke M, Fusaroli P, et al. EFSUMB guide- 
lines on interventional ultrasound (INVUS), part IV: EUSguided interventions: general aspects and EUS-guided sampling (short version). Ultraschall Med 2016;37:157-169.

73. Jenssen C, Hocke M, Fusaroli P, et al. EFSUMB guidelines on interventional ultrasound (INVUS), part IV: EUSguided interventions: general aspects and EUS-guided sampling (long version). Ultraschall Med 2016;37:E33-E76.

74. Fusaroli P, Jenssen C, Hocke M, et al. EFSUMB guidelines on interventional ultrasound (INVUS), part V: EUS-guided therapeutic interventions (short version). Ultraschall Med 2016;37:412-420.

75. Fusaroli P, Jenssen C, Hocke M, et al. EFSUMB guidelines on interventional ultrasound (INVUS), part V. Ultraschall Med 2016;37:77-99.

76. Hocke M, Dietrich C. Contrast-enhanced sonography and endoscopic ultrasound for the diagnosis of pancreatic diseases. Zentralbl Chir 2014;139:301-307.

77. Hocke M, Cui XW, Domagk D, Ignee A, Dietrich CF. Pancreatic cystic lesions: the value of contrast-enhanced endoscopic ultrasound to influence the clinical pathway. Endosc Ultrasound 2014;3:123-130.

78. Hocke M, Dietrich CF. Contrast-enhanced endoscopic ultrasound in the diagnosis of pancreatic diseases. Dtsch Med Wochenschr 2013;138:732-734.

79. Hocke M, Ignee A, Dietrich CF. Advanced endosonographic diagnostic tools for discrimination of focal chronic pancreatitis and pancreatic carcinoma: elastography, contrast enhanced high mechanical index (CEHMI) and low mechanical index (CELMI) endosonography in direct comparison. Z Gastroenterol 2012;50:199-203.

8o. Dietrich CF, Sharma M, Hocke M. Contrast-enhanced endoscopic ultrasound. Endosc Ultrasound 2012;1:130136.

81. Pietryga JA, Morgan DE. Imaging preoperatively for pancreatic adenocarcinoma. J Gastrointest Oncol 2015;6:343357.

82. Frampas E, Morla O, Regenet N, Eugene T, Dupas B, Meurette G. A solid pancreatic mass: tumour or inflammation? Diagn Interv Imaging 2013;94:741-755.

83. Hocke M, Dietrich CF. Vascularisation pattern of chronic pancreatitis compared with pancreatic carcinoma: results from contrast-enhanced endoscopic ultrasound. Int J Inflam 2012;2012:420787.

84. Itoh S, Yamakawa K, Shimamoto K, Endo T, Ishigaki T. CT findings in groove pancreatitis: correlation with histopathological findings. J Comput Assist Tomogr
1994;18:911-915.

85. Hocke M, Schmidt C, Zimmer B, Topalidis T, Dietrich CF, Stallmach A. Contrast enhanced endosonography for improving differential diagnosis between chronic pancreatitis and pancreatic cancer. Dtsch Med Wochenschr 2008;133:1888-1892.

86. Hirche TO, Ignee A, Barreiros AP, et al. Indications and limitations of endoscopic ultrasound elastography for evaluation of focal pancreatic lesions. Endoscopy 2008; 40:910-917.

87. Cosgrove D, Piscaglia F, Bamber J, et al. EFSUMB guidelines and recommendations on the clinical use of ultrasound elastography. Part 2: clinical applications. Ultraschall Med 2013;34:238-253.

88. Saftoiu A, Vilmann P, Gorunescu F, et al. Efficacy of an artificial neural network-based approach to endoscopic ultrasound elastography in diagnosis of focal pancreatic masses. Clin Gastroenterol Hepatol 2012;10:84-90.e1.

89. Dietrich CF, Saftoiu A, Jenssen C. Real time elastography endoscopic ultrasound (RTE-EUS), a comprehensive review. Eur J Radiol 2014;83:405-414.

90. Braden B, Jenssen C, D'Onofrio M, et al. B-mode and contrast-enhancement characteristics of small nonincidental neuroendocrine pancreatic tumors. Endosc Ultrasound 2017;6:49-54.

91. Iordache S, Angelescu R, Filip MM, et al. Power Doppler endoscopic ultrasound for the assessment of pancreatic neuroendocrine tumors. Endosc Ultrasound 2012;1:150-155.

92. Palazzo M. Role of contrast harmonic endoscopic ultrasonography in other pancreatic solid lesions: Neuroendocrine tumors, autoimmune pancreatitis and metastases. Endosc Ultrasound 2016;5:373-376.

93. Pang JC, Roh MH. Metastases to the pancreas encountered on endoscopic ultrasound-guided, fine-needle aspiration. Arch Pathol Lab Med 2015;139:1248-1252.

94. Pannala R, Hallberg-Wallace KM, Smith AL, et al. Endoscopic ultrasound-guided fine needle aspiration cytology of metastatic renal cell carcinoma to the pancreas: a multi-center experience. Cytojournal 2016;13:24.

95. Karakan T, Cengiz M, Ibis M, Akyurek N, Unal S. Pancreatic metastasis in a case of small cell lung carcinoma diagnosed by EUS. Turk J Gastroenterol 2015;26:53-55.

96. Anand D, Lall C, Bhosale P, Ganeshan D, Qayyum A. Current update on primary pancreatic lymphoma. Abdom Radiol (NY) 2016;41:347-355.

97. Mahajan R, Simon EG, Chacko A, et al. Endoscopic ul- 
trasonography in pediatric patients: experience from a tertiary care center in India. Indian J Gastroenterol 2016;35:14-19.

98. Law JK, Stoita A, Wever W, et al. Endoscopic ultrasoundguided fine needle aspiration improves the pre-operative diagnostic yield of solid-pseudopapillary neoplasm of the pancreas: an international multicenter case series (with video). Surg Endosc 2014;28:2592-2598.

99. Jung WS, Kim JK, Yu JS, Kim JH, Cho ES, Chung JJ. Comparison of abdominal ultrasonographic findings with endoscopic ultrasonographic findings of solid pseudopapillary neoplasms of the pancreas. Ultrasound Q 2014;30:173178.

100. Beyer-Enke SA, Hocke M, Ignee A, Braden B, Dietrich CF. Contrast enhanced transabdominal ultrasound in the characterisation of pancreatic lesions with cystic appearance. JOP 2010;11:427-433.

101. Jenssen C, Kahl S. Management of incidental pancreatic cystic lesions. Viszeralmedizin 2015;31:14-24.

102. Karoumpalis I, Christodoulou DK. Cystic lesions of the pancreas. Ann Gastroenterol 2016;29:155-161.

103. Seicean A, Badea R, Stan-Iuga R, Gulei I, Pop T, Pascu $O$. The added value of real-time harmonics contrastenhanced endoscopic ultrasonography for the characterisation of pancreatic diseases in routine practice. J Gastrointestin Liver Dis 2010;19:99-104.

104. Ketwaroo GA, Mortele KJ, Sawhney MS. Pancreatic cystic neoplasms: an update. Gastroenterol Clin North Am 2016;45:67-81.

105. Goh BK, Tan YM, Yap WM, et al. Pancreatic serous oligocystic adenomas: clinicopathologic features and a comparison with serous microcystic adenomas and mucinous cystic neoplasms. World J Surg 2006;30:1553-1559.

106. Nilsson LN, Keane MG, Shamali A, et al. Nature and management of pancreatic mucinous cystic neoplasm (MCN): a systematic review of the literature. Pancreatology 2016;16:1028-1036.

107. Tanaka M, Fernandez-del Castillo C, Adsay V, et al. International consensus guidelines 2012 for the management of IPMN and MCN of the pancreas. Pancreatology 2012;12:183-197.

108. Ohno E, Hirooka Y, Itoh A, et al. Intraductal papillary mucinous neoplasms of the pancreas: differentiation of malignant and benign tumors by endoscopic ultrasound findings of mural nodules. Ann Surg 2009;249:628-634. 109. Ohno E, Itoh A, Kawashima H, et al. Malignant trans- formation of branch duct-type intraductal papillary mucinous neoplasms of the pancreas based on contrastenhanced endoscopic ultrasonography morphological changes: focus on malignant transformation of intraductal papillary mucinous neoplasm itself. Pancreas 2012;41:855-862.

110. Yamashita Y, Ueda K, Itonaga M, et al. Usefulness of contrast-enhanced endoscopic sonography for discriminating mural nodules from mucous clots in intraductal papillary mucinous neoplasms: a single-center prospective study. J Ultrasound Med 2013;32:61-68.

111. Fujita M, Itoi T, Ikeuchi N, et al. Effectiveness of contrastenhanced endoscopic ultrasound for detecting mural nodules in intraductal papillary mucinous neoplasm of the pancreas and for making therapeutic decisions. Endosc Ultrasound 2016;5:377-383.

112. Fusaroli P, Serrani M, De Giorgio R, et al. Contrast harmonic-endoscopic ultrasound is useful to identify neoplastic features of pancreatic cysts (with videos). Pancreas 2016;45:265-268.

113. Kamata K, Kitano M, Omoto S, et al. Contrast-enhanced harmonic endoscopic ultrasonography for differential diagnosis of pancreatic cysts. Endoscopy 2016;48:35-41.

114. Yamamoto N, Kato H, Tomoda T, et al. Contrast-enhanced harmonic endoscopic ultrasonography with time-intensity curve analysis for intraductal papillary mucinous neoplasms of the pancreas. Endoscopy 2016;48:26-34.

115. Chiorean L, Cui XW, Klein SA, et al. Clinical value of imaging for lymph nodes evaluation with particular emphasis on ultrasonography. Z Gastroenterol 2016;54:774-790.

116. Dietrich CF, Jenssen C, Arcidiacono PG, et al. Endoscopic ultrasound: elastographic lymph node evaluation. Endosc Ultrasound 2015;4:176-190.

117. Dietrich CF, Annema JT, Clementsen P, Cui XW, Borst MM, Jenssen C. Ultrasound techniques in the evaluation of the mediastinum, part I: endoscopic ultrasound (EUS), endobronchial ultrasound (EBUS) and transcutaneous mediastinal ultrasound (TMUS), introduction into ultrasound techniques. J Thorac Dis 2015;7: $\mathrm{E}_{311}-\mathrm{E}_{3} 25$.

118. Dietrich CF, Jenssen C, Herth FJ. Endobronchial ultrasound elastography. Endosc Ultrasound 2016;5:233-238.

119. Jenssen C, Annema JT, Clementsen P, Cui XW, Borst MM, Dietrich CF. Ultrasound techniques in the evaluation of the mediastinum, part 2: mediastinal lymph node anatomy and diagnostic reach of ultrasound techniques, clinical work up of neoplastic and inflammatory medias- 
tinal lymphadenopathy using ultrasound techniques and how to learn mediastinal endosonography. J Thorac Dis 2015;7:E439-E458.

120. Sharma M, Rameshbabu CS, Dietrich CF, Rai P, Bansal R. Endoscopic ultrasound of the hepatoduodenal ligament and liver hilum. Endosc Ultrasound 2016 Nov 8 [Epub]. https://doi.org/10.4103/2303-9027.193584.

121. Hirche TO, Russler J, Braden B, et al. Sonographic detection of perihepatic lymphadenopathy is an indicator for primary sclerosing cholangitis in patients with inflammatory bowel disease. Int J Colorectal Dis 2004;19:586594.

122. Dietrich CF, Stryjek-Kaminska D, Teuber G, Lee JH, Caspary WF, Zeuzem S. Perihepatic lymph nodes as a marker of antiviral response in patients with chronic hepatitis $\mathrm{C}$ infection. AJR Am J Roentgenol 2000;174:699-704.

123. Dietrich CF, Leuschner MS, Zeuzem S, et al. Peri-hepatic lymphadenopathy in primary biliary cirrhosis reflects progression of the disease. Eur J Gastroenterol Hepatol 1999;11:747-753.

124. Dietrich CF, Lee JH, Herrmann G, et al. Enlargement of perihepatic lymph nodes in relation to liver histology and viremia in patients with chronic hepatitis C. Hepatology 1997;26:467-472.

125. Dietrich CF, Gottschalk R, Herrmann G, Caspary WF, Zeuzem S. Sonographic detection of lymph nodes in the hepatoduodenal ligament. Dtsch Med Wochenschr 1997;122:1269-1274.

126. Tio TL, Kallimanis GE. Endoscopic ultrasonography of perigastrointestinal lymph nodes. Endoscopy 1994;26:776779 .

127. Ahuja A, Ying M, Evans R, King W, Metreweli C. The application of ultrasound criteria for malignancy in differentiating tuberculous cervical adenitis from metastatic nasopharyngeal carcinoma. Clin Radiol 1995:50:391-395.

128. Dragoni F, Cartoni C, Pescarmona E, et al. The role of high resolution pulsed and color Doppler ultrasound in the differential diagnosis of benign and malignant lymphadenopathy: results of multivariate analysis. Cancer 1999;85:2485-2490.

129. Miyata T, Kitano M, Omoto S, et al. Contrast-enhanced harmonic endoscopic ultrasonography for assessment of lymph node metastases in pancreatobiliary carcinoma. World J Gastroenterol 2016;22:3381-3391.

130. Cui XW, Jenssen C, Saftoiu A, Ignee A, Dietrich CF. New ultrasound techniques for lymph node evaluation. World
J Gastroenterol 2013;19:4850-4860.

131. Hocke M, Menges M, Topalidis T, Dietrich CF, Stallmach A. Contrast-enhanced endoscopic ultrasound in discrimination between benign and malignant mediastinal and abdominal lymph nodes. J Cancer Res Clin Oncol 2008; 134:473-48o.

132. Bamber J, Cosgrove D, Dietrich CF, et al. EFSUMB guidelines and recommendations on the clinical use of ultrasound elastography. Part 1: basic principles and technology. Ultraschall Med 2013;34:169-184.

133. Saftoiu A, Vilmann P, Hassan H, Gorunescu F. Analysis of endoscopic ultrasound elastography used for characterisation and differentiation of benign and malignant lymph nodes. Ultraschall Med 2006;27:535-542.

134. Bhutani MS, Nadella P. Utility of an upper echoendoscope for endoscopic ultrasonography of malignant and benign conditions of the sigmoid/left colon and the rectum. Am J Gastroenterol 2001;96:3318-3322.

135. Li XT, Zhang XY, Sun YS, Tang L, Cao K. Evaluating rectal tumor staging with magnetic resonance imaging, computed tomography, and endoluminal ultrasound: a metaanalysis. Medicine (Baltimore) 2016;95:e5333.

136. Fernandez Ananin S, Targarona EM, Martinez C, et al. Predicting the pathological features of the mesorectum before the laparoscopic approach to rectal cancer. Surg Endosc 2014;28:3458-3466.

137. Otto SD, Lee L, Buhr HJ, Frericks B, Hocht S, Kroesen AJ. Staging anal cancer: prospective comparison of transanal endoscopic ultrasound and magnetic resonance imaging. J Gastrointest Surg 2009;13:1292-1298.

138. Barreiros AP, Hirche TO, Ignee A, Nurnberg D, Dietrich CF. Indications and limitations of perineal ultrasound examination. Scand J Gastroenterol 2010;45:764-765.

139. Allgayer H, Dietrich CF, Rohde W, Koch GF, Tuschhoff T. Prospective comparison of short- and long-term effects of pelvic floor exercise/biofeedback training in patients with fecal incontinence after surgery plus irradiation versus surgery alone for colorectal cancer: clinical, functional and endoscopic/endosonographic findings. Scand J Gastroenterol 2005;40:1168-1175.

140. Lahat A, Assulin Y, Beer-Gabel M, Chowers Y. Endoscopic ultrasound for perianal Crohn's disease: disease and fistula characteristics, and impact on therapy. J Crohns Colitis 2012;6:311-316.

141. Hirche TO, Russler J, Schroder O, et al. The value of routinely performed ultrasonography in patients with Crohn 
disease. Scand J Gastroenterol 2002;37:1178-1183.

142. Schreiber-Dietrich D, Chiorean L, Cui XW, et al. Particularities of Crohn's disease in pediatric patients: current status and perspectives regarding imaging modalities. Expert Rev Gastroenterol Hepatol 2015;9:1313-1325.

143. Saranovic D, Krivokapic Z, Masulovic D, et al. Endoanal ultrasonography in establishing the diagnosis of fecal incontinence. Acta Chir Iugosl 2007;54:159-162.

144. Italian Society of Colorectal Surgery (SICCR), Pucciani F, Altomare DF, et al. Diagnosis and treatment of faecal incontinence: consensus statement of the Italian Society of Colorectal Surgery and the Italian Association of Hospital Gastroenterologists. Dig Liver Dis 2015;47:628-645.

145. Fritscher-Ravens A, Sriram PV, Topalidis T, et al. Diagnosing sarcoidosis using endosonography-guided fineneedle aspiration. Chest 2000;118:928-935.

146. Tang SJ, Vilmann AS, Saftoiu A, et al. EUS needle identification comparison and evaluation study (with videos). Gastrointest Endosc 2016;84:424-433.e2.

147. Bang JY, Varadarajulu S. Procore and flexible 19 gauge needle can replace trucut biopsy needle? Clin Endosc 2013;46:503-505.

148. Bang JY, Hawes R, Varadarajulu S. A meta-analysis comparing ProCore and standard fine-needle aspiration needles for endoscopic ultrasound-guided tissue acquisition. Endoscopy 2016;48:339-349

149. Kandel P, Tranesh G, Nassar A, et al. EUS-guided fine needle biopsy sampling using a novel fork-tip needle: a case-control study. Gastrointest Endosc 2016;84:1034-1039.

150. Adler DG, Witt B, Chadwick B, et al. Pathologic evaluation of a new endoscopic ultrasound needle designed to obtain core tissue samples: a pilot study. Endosc Ultrasound 2016;5:178-183.

151. DiMaio CJ, Kolb JM, Benias PC, et al. Initial experience with a novel EUS-guided core biopsy needle (SharkCore): results of a large North American multicenter study. Endosc Int Open 2016;4:E974-E979.

152. Bang JY, Hebert-Magee S, Hasan MK, Navaneethan U, Hawes R, Varadarajulu S. Endoscopic ultrasonographyguided biopsy using a Franseen needle design: initial assessment. Dig Endosc 2017;29:338-346.

153. El Chafic AH, Loren D, Siddiqui A, Mounzer R, Cosgrove N, Kowalski T. Comparison of FNA and fine-needle biopsy for EUS-guided sampling of suspected GI stromal tumors. Gastrointest Endosc 2017;86:510-515.

154. Kim JH, Park SW, Kim MK, et al. Meta-analysis for cyto- pathological outcomes in endoscopic ultrasonographyguided fine-needle aspiration with and without the stylet. Dig Dis Sci 2016;61:2175-2184.

155. Park SW, Chung MJ, Lee SH, et al. Prospective study for comparison of endoscopic ultrasound-guided tissue acquisition using 25- and 22-gauge core biopsy needles in solid pancreatic masses. PLoS One 2016;11:e0154401.

156. Chen JY, Ding QY, Lv Y, et al. Slow-pull and different conventional suction techniques in endoscopic ultrasound-guided fine-needle aspiration of pancreatic solid lesions using 22-gauge needles. World J Gastroenterol 2016;22:8790-8797.

157. de Luna R, Eloubeidi MA, Sheffield MV, et al. Comparison of ThinPrep and conventional preparations in pancreatic fine-needle aspiration biopsy. Diagn Cytopathol 2004;30:71-76.

158. LeBlanc JK, Emerson RE, Dewitt J, et al. A prospective study comparing rapid assessment of smears and ThinPrep for endoscopic ultrasound-guided fine-needle aspirates. Endoscopy 2010;42:389-394.

159. Yun SS, Remotti H, Vazquez MF, Crapanzano JP, Saqi A. Endoscopic ultrasound-guided biopsies of pancreatic masses: comparison between fine needle aspirations and needle core biopsies. Diagn Cytopathol 2007;35:276-282.

160. Skov BG, Baandrup U, Jakobsen GK, et al. Cytopathologic diagnoses of fine-needle aspirations from endoscopic ultrasound of the mediastinum: reproducibility of the diagnoses and representativeness of aspirates from lymph nodes. Cancer 2007;111:234-241.

161. Hocke M, Ignee A, Topalidis T, Dietrich CF. Back to the roots: should gastroenterologists perform their own cytology? Z Gastroenterol 2013;51:191-195.

162. Bocking A, Pomjansky N, Buckstegge B, Onofre A. Immunocytochemical identification of carcinomas of unknown primaries on fine-needle-aspiration-biopsies. Pathologe 2009;30 Suppl 2:158-160.

163. Lindsey KG, Houser PM, Shotsberger-Gray W, Chajewski OS, Yang J. Young investigator challenge: a novel, simple method for cell block preparation, implementation, and use over 2 years. Cancer 2016;124:885-892.

164. Ieni A, Barresi V, Todaro P, Caruso RA, Tuccari G. Cellblock procedure in endoscopic ultrasound-guided-fineneedle-aspiration of gastrointestinal solid neoplastic lesions. World J Gastrointest Endosc 2015;7:1014-1022.

165. Alvarez-Sanchez MV, Jenssen C, Faiss S, Napoleon B. Interventional endoscopic ultrasonography: an overview of 
safety and complications. Surg Endosc 2014;28:712-734.

166. Jenssen C, Faiss S, Nurnberg D. Complications of endoscopic ultrasound and endoscopic ultrasound-guided interventions: results of a survey among German centers. Z Gastroenterol 2008;46:1177-1184.

167. Sun L, Lu L, Fu W, Li W, Liu T. Gastric bronchogenic cyst presenting as a gastrointestinal stromal tumor. Int J Clin Exp Pathol 2015;8:13606-13612.

168. Antonini F, Fuccio L, Fabbri C, Macarri G, Palazzo L. Management of serous cystic neoplasms of the pancreas. Expert Rev Gastroenterol Hepatol 2015;9:115-125.

169. Hackert T, Fritz S, Klauss M, et al. Main-duct intraductal papillary mucinous neoplasm: high cancer risk in duct diameter of 5 to $9 \mathrm{~mm}$. Ann Surg 2015;262:875-88o.

170. Crippa S, Bassi C, Salvia R, et al. Low progression of intraductal papillary mucinous neoplasms with worrisome features and high-risk stigmata undergoing nonoperative management: a mid-term follow-up analysis. Gut 2017;66:495-506.

171. Sakorafas GH, Smyrniotis V, Reid-Lombardo KM, Sarr MG. Primary pancreatic cystic neoplasms revisited: part II. Mucinous cystic neoplasms. Surg Oncol 2011;20:e93-e101.

172. Bick BL, Enders FT, Levy MJ, et al. The string sign for diagnosis of mucinous pancreatic cysts. Endoscopy 2015;47:626-631.

173. Linder JD, Geenen JE, Catalano MF. Cyst fluid analysis obtained by EUS-guided FNA in the evaluation of discrete cystic neoplasms of the pancreas: a prospective single-center experience. Gastrointest Endosc 2006;64:697702.

174. Sand JA, Hyoty MK, Mattila J, Dagorn JC, Nordback IH. Clinical assessment compared with cyst fluid analysis in the differential diagnosis of cystic lesions in the pancreas. Surgery 1996;119:275-280.

175. Oh SH, Lee JK, Lee KT, Lee KH, Woo YS, Noh DH. The combination of cyst fluid carcinoembryonic antigen, cytology and viscosity increases the diagnostic accuracy of mucinous pancreatic cysts. Gut Liver 2017;11:283-289.

176. Al-Haddad M, DeWitt J, Sherman S, et al. Performance characteristics of molecular (DNA) analysis for the diagnosis of mucinous pancreatic cysts. Gastrointest Endosc 2014;79:79-87.

177. Singhi AD, Zeh HJ, Brand RE, et al. American Gastroenterological Association guidelines are inaccurate in detecting pancreatic cysts with advanced neoplasia: a clinicopathologic study of 225 patients with supporting molecular data. Gastrointest Endosc 2016;83:1107-1117.e2. 178. Guo X, Zhan X, Li Z. Molecular analyses of aspirated cystic fluid for the differential diagnosis of cystic lesions of the pancreas: a systematic review and meta-analysis. Gastroenterol Res Pract 2016;2016:3546085.

179. Lee JH, Kim Y, Choi JW, Kim YS. KRAS, GNAS, and RNF43 mutations in intraductal papillary mucinous neoplasm of the pancreas: a meta-analysis. Springerplus 2016;5:1172.

180. Allen PJ, D'Angelica M, Gonen M, et al. A selective approach to the resection of cystic lesions of the pancreas: results from 539 consecutive patients. Ann Surg 2006;244:572-582.

181. Sahani DV, Saokar A, Hahn PF, Brugge WR, Fernandez-Del Castillo C. Pancreatic cysts $3 \mathrm{~cm}$ or smaller: how aggressive should treatment be? Radiology 2006;238:912-919.

182. Ito $\mathrm{H}$, Inoue $\mathrm{H}$, Ryozawa $\mathrm{S}$, et al. Fine-needle aspiration biopsy and endoscopic ultrasound for pretreatment pathological diagnosis of gastric gastrointestinal stromal tumors. Gastroenterol Res Pract 2012;2012:139083.

183. Jenssen C, Moller K, Wagner S, Sarbia M. Endoscopic ultrasound-guided biopsy: diagnostic yield, pitfalls, quality management part 1 : optimizing specimen collection and diagnostic efficiency. Z Gastroenterol 2008;46:590-60o.

184. Vilmann P, Clementsen PF, Colella S, et al. Combined endobronchial and esophageal endosonography for the diagnosis and staging of lung cancer: European Society of Gastrointestinal Endoscopy (ESGE) Guideline, in cooperation with the European Respiratory Society (ERS) and the European Society of Thoracic Surgeons (ESTS). Endoscopy 2015;47:545-559.

185. Dietrich CF. Contrast-enhanced endobronchial ultrasound: potential value of a new method. Endosc Ultrasound 2017;6:43-48.

186. Zhao H, Xie Z, Zhou ZL, Sui XZ, Wang J. Diagnostic value of endobronchial ultrasound-guided transbronchial needle aspiration in intrapulmonary lesions. Chin Med J (Engl) 2013;126:4312-4315.

187. Vigliar E, Malapelle U, Bellevicine C, de Luca C, Troncone G. Outsourcing cytological samples to a referral laboratory for EGFR testing in non-small cell lung cancer: does theory meet practice? Cytopathology 2015;26:312-317.

188. Song HJ, Kim JO, Eun SH, et al. Endoscopic ultrasonograpic findings of benign mediastinal and abdominal lymphadenopathy confirmed by EUS-guided fine needle aspiration. Gut Liver 2007;1:68-73.

189. Ribeiro C, Oliveira A, Neves S, et al. Diagnosis of sarcoid- 
osis in the endobronchial ultrasound-guided transbronchial needle aspiration era. Rev Port Pneumol 2014;20:237241.

190. Talebian Yazdi M, von Bartheld MB, Waaijenborg FG, et al. Endosonography for the diagnosis of malignant lymphoma presenting with mediastinal lymphadenopathy. J Bronchology Interv Pulmonol 2014;21:298-305.

191. Sharma M, Ecka RS, Somasundaram A, Shoukat A, Kirnake V. Endoscopic ultrasound in mediastinal tuberculosis. Lung India 2016;33:129-134.

192. Barreiros AP, Braden B, Schieferstein-Knauer C, Ignee A, Dietrich CF. Characteristics of intestinal tuberculosis in ultrasonographic techniques. Scand J Gastroenterol 2008;43:1224-1231.

193. Dietrich CF, Wehrmann T, Hoffmann C, Herrmann G, Caspary WF, Seifert H. Detection of the adrenal glands by endoscopic or transabdominal ultrasound. Endoscopy 1997;29:859-864.

194. Dietrich CF, Ignee A, Barreiros AP, et al. Contrast-enhanced ultrasound for imaging of adrenal masses. Ultraschall Med 2010;31:163-168.

195. Barreiros AP, Chiorean L, Braden B, Dietrich CF. Ultrasound in rare diffuse liver disease. Z Gastroenterol 2014;52:1247-1256.

196. Ignee A, Cui X, Hirche T, et al. Percutaneous biopsies of splenic lesions: a clinical and contrast enhanced ultrasound based algorithm. Clin Hemorheol Microcirc 2014;58:529-541.

197. Trojan J, Schwarz W, Sarrazin C, Thalhammer A, Vogl TJ, Dietrich CF. Role of ultrasonography in the detection of small adrenal masses. Ultraschall Med 2002;23:96-100.

198. Patil R, Ona MA, Papafragkakis C, Duddempudi S, Anand S, Jamil LH. Endoscopic ultrasound-guided fine-needle aspiration in the diagnosis of adrenal lesions. Ann Gastroenterol 2016;29:307-311.

199. Jenssen C, Dietrich CF. Ultrasound and endoscopic ultrasound of the adrenal glands. Ultraschall Med 2010;31:228247.

200. DeWitt JM. Endoscopic ultrasound-guided fine-needle aspiration of right adrenal masses: report of 2 cases. J Ultrasound Med 2008;27:261-267.

201. Sadeghi A, Mohamadnejad M, Islami F, et al. Diagnostic yield of EUS-guided FNA for malignant biliary stricture: a systematic review and meta-analysis. Gastrointest Endosc 2016;83:290-298.e1.

202. Hammoud GM, Almashhrawi A, Ibdah JA. Usefulness of endoscopic ultrasound-guided fine needle aspiration in the diagnosis of hepatic, gallbladder and biliary tract Lesions. World J Gastrointest Oncol 2014;6:420-429.

203. Handa U, Tiwari A, Singhal N, Mohan H, Kaur R. Utility of ultrasound-guided fine-needle aspiration in splenic lesions. Diagn Cytopathol 2013;41:1038-1042.

204. Korevaar DA, Colella S, Spijker R, et al. Esophageal endosonography for the diagnosis of intrapulmonary tumors: a systematic review and meta-analysis. Respiration 2017;93:126-137.

205. Gunaratnam NT, Sarma AV, Norton ID, Wiersema MJ. A prospective study of EUS-guided celiac plexus neurolysis for pancreatic cancer pain. Gastrointest Endosc 2001;54:316-324.

206. Chantarojanasiri T, Aswakul P, Prachayakul V. Uncommon complications of therapeutic endoscopic ultrasonography: what, why, and how to prevent. World J Gastrointest Endosc 2015;7:960-968.

207. Armellini E, Crino SF, Ballare M, Pallio S, Occhipinti P. Endoscopic ultrasound-guided ethanol ablation of pancreatic neuroendocrine tumours: a case study and literature review. World J Gastrointest Endosc 2016;8:192-197.

208. Jurgensen C, Schuppan D, Neser F, Ernstberger J, Junghans U, Stolzel U. EUS-guided alcohol ablation of an insulinoma. Gastrointest Endosc 2006;63:1059-1062.

209. Dietrich CF, Chiorean L, Potthoff A, Ignee A, Cui X, Sparchez Z. Percutaneous sclerotherapy of liver and renal cysts, comments on the EFSUMB guidelines. Z Gastroenterol 2016;54:155-166.

210. Park JS, Seo DW, Song TJ, et al. Endoscopic ultrasoundguided ablation of branch-duct intraductal papillary mucinous neoplasms: feasibility and safety tests using porcine gallbladders. Dig Endosc 2016;28:599-606.

211. Vazquez-Sequeiros E, Maluf-Filho F. Endosonographyguided ablation of pancreatic cystic tumors: Is it justified? Gastrointest Endosc 2016;83:921-923.

212. Majumder S, Berzin TM, Mahadevan A, et al. Endoscopic ultrasound-guided pancreatic fiducial placement: how important is ideal fiducial geometry? Pancreas 2013;42:692-695.

213. Besselink MG, de Bruijn MT, Rutten JP, et al. Surgical intervention in patients with necrotizing pancreatitis. $\mathrm{Br}$ J Surg 2006;93:593-599.

214. Seifert H, Wehrmann T, Schmitt T, Zeuzem S, Caspary WF. Retroperitoneal endoscopic debridement for infected peripancreatic necrosis. Lancet 2000;356:653-655. 
215. Dietrich CF, Hocke M, Jenssen C. Interventional endosonography. Ultraschall Med 2011;32:8-22.

216. Braden B, Dietrich CF. Endoscopic ultrasonographyguided endoscopic treatment of pancreatic pseudocysts and walled-off necrosis: new technical developments. World J Gastroenterol 2014;20:16191-16196.

217. Seifert H, Dietrich C, Schmitt T, Caspary W, Wehrmann T. Endoscopic ultrasound-guided one-step transmural drainage of cystic abdominal lesions with a large-channel echo endoscope. Endoscopy 2000;32:255-259.

218. Seifert H, Faust D, Schmitt T, Dietrich C, Caspary W, Wehrmann T. Transmural drainage of cystic peripancreatic lesions with a new large-channel echo endoscope. Endoscopy 2001;33:1022-1026.

219. Bang JY, Varadarajulu S. Management of walled-off necrosis using the multiple transluminal gateway technique with the Hot AXIOS System. Dig Endosc 2016;28:103.

220. Hocke M, Will U, Gottschalk P, Settmacher U, Stallmach A. Transgastral retroperitoneal endoscopy in septic patients with pancreatic necrosis or infected pancreatic pseudocysts. Z Gastroenterol 2008;46:1363-1368.

221. Dietrich CF, Rudd L, Saftiou A, Gilja OH. The EFSUMB website, a great source for ultrasound information and education. Med Ultrason 2017;19:102-110.

222. Lorentzen T, Nolsoe CP, Ewertsen C, et al. EFSUMB guidelines on interventional ultrasound (INVUS), part I: general aspects (long version). Ultraschall Med 2015;36:E1-E14.

223. Lorentzen T, Nolsoe CP, Ewertsen C, et al. EFSUMB guidelines on interventional ultrasound (INVUS), part I: general aspects (short version). Ultraschall Med 2015;36:464-472.

224. Sidhu PS, Brabrand K, Cantisani V, et al. EFSUMB guidelines on interventional ultrasound (INVUS), part II: diagnostic ultrasound-guided interventional procedures (long version). Ultraschall Med 2015;36:E15-E35.

225. Sidhu PS, Brabrand K, Cantisani V, et al. EFSUMB guidelines on interventional ultrasound (INVUS), part II: diagnostic ultrasound-guided interventional procedures (short version). Ultraschall Med 2015;36:566-580.

226. Dietrich CF, Lorentzen T, Appelbaum L, et al. EFSUMB guidelines on interventional ultrasound (INVUS), part III: abdominal treatment procedures (short version). Ultraschall Med 2016;37:27-45.

227. Dietrich CF, Lorentzen T, Appelbaum L, et al. EFSUMB guidelines on interventional ultrasound (INVUS), part III: abdominal treatment procedures (long version). U1- traschall Med 2016;37:E1-E32.

228. Dietrich CF, Lorentzen T, Sidhu PS, et al. An introduction to the EFSUMB guidelines on interventional ultrasound (INVUS). Ultraschall Med 2015;36:460-463.

229. Dietrich CF. EFSUMB guidelines 2015 on interventional ultrasound. Med Ultrason 2015;17:521-527.

230. Burmester E, Niehaus J, Leineweber T, Huetteroth T. EUS-cholangio-drainage of the bile duct: report of 4 cases. Gastrointest Endosc 2003;57:246-251.

231. Will U, Thieme A, Fueldner F, Gerlach R, Wanzar I, Meyer F. Treatment of biliary obstruction in selected patients by endoscopic ultrasonography (EUS)-guided transluminal biliary drainage. Endoscopy 2007;39:292-295.

232. Khan MA, Akbar A, Baron TH, et al. Endoscopic ultrasound-guided biliary drainage: a systematic review and meta-analysis. Dig Dis Sci 2016;61:684-703.

233. Wang K, Zhu J, Xing L, Wang Y, Jin Z, Li Z. Assessment of efficacy and safety of EUS-guided biliary drainage: a systematic review. Gastrointest Endosc 2016;83:1218-1227.

234. Sharaiha RZ, Khan MA, Kamal F, et al. Efficacy and safety of EUS-guided biliary drainage in comparison with percutaneous biliary drainage when ERCP fails: a systematic review and meta-analysis. Gastrointest Endosc 2017;85:904-914.

235. Lee TH, Choi JH, Park DH, et al. Similar efficacies of endoscopic ultrasound-guided transmural and percutaneous drainage for malignant distal biliary obstruction. Clin Gastroenterol Hepatol 2016;14:1011-1019.e3.

236. Will U, Meyer F. Endoscopic ultrasonography (EUS)guided transluminal cholangiodrainage (EUCD): a novel option of interventional endoscopy in the interdiciplinary management of obstructive jaundice. Zentralbl Chir 2012;137:20-31.

237. Tyberg A, Saumoy M, Sequeiros EV, et al. EUS-guided versus percutaneous gallbladder drainage: isn't it time to convert? J Clin Gastroenterol 2018;52:79-84.

238. Dollhopf M, Larghi A, Will U, et al. Eus-guided gallbladder drainage in patients with acute cholecystitis and high surgical risk using an electrocautery-enhanced lumen-apposing metal stent device. Gastrointest Endosc 2017;86:636-643

239. Irani S, Ngamruengphong S, Teoh A, et al. Similar efficacies of endoscopic ultrasound gallbladder drainage with a lumen-apposing metal stent versus percutaneous transhepatic gallbladder drainage for acute cholecystitis. Clin Gastroenterol Hepatol 2017;15:738-745. 
240. Teoh AY, Serna C, Penas I, et al. Endoscopic ultrasound-guided gallbladder drainage reduces adverse events compared with percutaneous cholecystostomy in patients who are unfit for cholecystectomy. Endoscopy 2017;49:130-138.

241. Will U, Reichel A, Fueldner F, Meyer F. Endoscopic ultrasonography-guided drainage for patients with symptomatic obstruction and enlargement of the pancreatic duct. World J Gastroenterol 2015;21:13140-13151.

242. Chen YI, Levy MJ, Moreels TG, et al. An international multicenter study comparing EUS-guided pancreatic duct drainage with enteroscopy-assisted endoscopic retrograde pancreatography after Whipple surgery. Gastrointest Endosc 2017;85:170-177.

243. Tyberg A, Sharaiha RZ, Kedia P, et al. EUS-guided pancreatic drainage for pancreatic strictures after failed ERCP: a multicenter international collaborative study. Gastrointest Endosc 2017;85:164-169.

244. Will U, Fuldner F, Reichel A, Meyer F. EUS-guided drainage of the pancreatic duct (EUPD): promising therapeutic alternative to surgical intervention in case of symptomatic retention of the pancreatic duct and unsuccessful ERP. Zentralbl Chir 2014;139:318-325.

245. Dietrich CF, Ignee A, Frey H. Contrast-enhanced endoscopic ultrasound with low mechanical index: a new technique. Z Gastroenterol 2005;43:1219-1223.

246. Giovannini M. Contrast-enhanced and 3-dimensional endoscopic ultrasonography. Gastroenterol Clin North Am 2010;39:845-858.

247. Dietrich CF, Averkiou MA, Correas JM, Lassau N, Leen E, Piscaglia F. An EFSUMB introduction into dynamic contrast-enhanced ultrasound (DCE-US) for quantification of tumour perfusion. Ultraschall Med 2012;33:344-351. 248. Shirley LA, Aguilar LK, Aguilar-Cordova E, Bloomston M, Walker JP. Therapeutic endoscopic ultrasonography: intratumoral injection for pancreatic adenocarcinoma. Gastroenterol Res Pract 2013;2013:207129.

249. Tardy I, Pochon S, Theraulaz M, et al. Ultrasound molecular imaging of VEGFR2 in a rat prostate tumor model using BR55. Invest Radiol 2010;45:573-578.

250. Dimcevski G, Kotopoulis S, Bjanes T, et al. A human clinical trial using ultrasound and microbubbles to enhance gemcitabine treatment of inoperable pancreatic cancer. J Control Release 2016;243:172-181.

251. Kotopoulis S, Delalande A, Popa M, et al. Sonoporation-enhanced chemotherapy significantly reduces primary tumour burden in an orthotopic pancreatic cancer xenograft. Mol Imaging Biol 2014;16:53-62.

252. Chen YI, Itoi T, Baron TH, et al. EUS-guided gastroenterostomy is comparable to enteral stenting with fewer re-interventions in malignant gastric outlet obstruction. Surg Endosc 2017;31:2946-2952.

253. Itoi T, Ishii K, Ikeuchi N, et al. Prospective evaluation of endoscopic ultrasonography-guided double-balloon-occluded gastrojejunostomy bypass (EPASS) for malignant gastric outlet obstruction. Gut 2016;65:193-195.

254. Itoi T, Tsuchiya T, Tonozuka R, Ijima M, Kusano C. Novel EUS-guided double-balloon-occluded gastrojejunostomy bypass. Gastrointest Endosc 2016;83:461-462.

255. Tyberg A, Perez-Miranda M, Sanchez-Ocana R, et al. Endoscopic ultrasound-guided gastrojejunostomy with a lumen-apposing metal stent: a multicenter, international experience. Endosc Int Open 2016;4:E276-E281. 